\title{
RGD(F/S/V)-Dex: towards the development of novel, effective, and safe glucocorticoids
}

\author{
This article was published in the following Dove Press journal: \\ Drug Design, Development and Therapy \\ 8 March 2016 \\ Number of times this article has been viewed
}

\author{
Xueyun Jiang' \\ Ming Zhaol,2 \\ Yuji Wang' \\ Haimei Zhu' \\ Shurui Zhao' \\ Jianhui Wu' \\ Yuanbo Song ${ }^{3}$ \\ Shiqi Peng' \\ 'Beijing Area Major Laboratory of \\ Peptide and Small Molecular Drugs, \\ Engineering Research Center of \\ Endogenous Prophylactic of Ministry \\ of Education of China, Beijing \\ Laboratory of Biomedical Materials, \\ College of Pharmaceutical Sciences, \\ Capital Medical University, Beijing, \\ People's Republic of China; ${ }^{2}$ Faculty of \\ Biomedical Science and Environmental \\ Biology, Kaohsiung Medical University, \\ Kaohsiung, Taiwan; ${ }^{3}$ Guangxi Pusen \\ Biotechnology Co. Ltd., Nanning, \\ Guangxi, People's Republic of China
}

Correspondence: Ming Zhao; Shiqi Peng Beijing Area Major Laboratory of Peptide And Small Molecular Drugs, Engineering Research Center of Endogenous Prophylactic of Ministry of Education of China, Beijing Laboratory of Biomedical Materials, College of Pharmaceutical Sciences, Capital Medical University, Beijing 100069, People's Republic of China

Email mingzhao@bjmu.edu.cn; sqpeng@bjmu.edu.cn

\begin{abstract}
Dexamethasone (Dex) is an effective glucocorticoid in treating inflammation and preventing rejection reaction. However, the side effects limit its clinical application. To improve its druggable profile, the conjugates of RGD-peptide-modified Dex were presented and their enhanced anti-inflammation activity, minimized osteoporotic action, and nanoscaled assembly were explored. (RGD stands for Arg-Gly-Asp. Standard single letter biochemical abbreviations for amino acids have been used throughout this paper.) In respect of the rejection reaction, the survival time of the implanted myocardium of the mice treated with $1.43 \mu \mathrm{mol} / \mathrm{kg} / \mathrm{d}$ of the conjugates for 15 consecutive days was significantly longer than that of the mice treated with $2.5 \mu \mathrm{mol} / \mathrm{kg} / \mathrm{d}$ of Dex, and the conjugates, but not Dex, exhibited no toxic action. At a single dose of $14.3 \mu \mathrm{mol} / \mathrm{kg}$ (100 times minimal effective dose, $0.143 \mu \mathrm{mol} / \mathrm{kg}$ ), the conjugates induced no liver, kidney, or systemic toxicity. At the dose of $1.43 \mu \mathrm{mol} / \mathrm{kg}$, the conjugates, but not Dex, prolonged the bleeding time of the mice, and inhibited the thrombosis of the rats. In water and rat plasma, the conjugates formed nanoparticles of 14-250 and 101-166 nm in diameter, respectively. Since the nanoparticles of $\sim 100 \mathrm{~nm}$ in size cannot be entrapped by macrophages in the circulation, RGDF-Dex would particularly be worthy of development, since its nanoparticle diameter is $101 \mathrm{~nm}$.
\end{abstract}

Keywords: Dexamethasone, immunosuppression, coagulation, thrombus, acute toxicity, nanomedicine, development

\section{Introduction}

As one of most effective glucocorticoids, dexamethasone (Dex) is clinically used to treat inflammatory diseases, ${ }^{1,2}$ rheumatoid arthritis, ${ }^{3-5}$ postoperative induced nausea and vomiting, and low-level emetogenic chemotherapy/radiotherapy. ${ }^{6-8}$ It has also been used to treat castration-resistant prostate cancer, ${ }^{9}$ postoperative pain, ${ }^{10}$ diabetic macular edema, as well as asthma exacerbation. ${ }^{11,12}$ In addition, Dex is an effective therapeutic for treating primary immune thrombocytopenia and perioperative immunosuppression of cardiac transplantation, preventing rejection of the transplanted organ, and preserving graft function. ${ }^{13-16}$

However, the clinical use of Dex is limited by its side effects. In cardiac surgery, intraoperative high-dose of Dex is associated with rethoracotomy risk. ${ }^{17}$ A single dose of Dex was associated with myocardial hypertrophy of laryngeal edema in a preterm infant. ${ }^{18}$ For patients in valvular cardiac surgery, high-dose Dex has no protective effect on the occurrence of postpericardiotomy syndrome, ${ }^{19}$ while low-dose Dex may worsen the survival of surgery patients with rectal cancer. ${ }^{20}$ The psychiatric and cognitive symptoms resembling major depression could be observed in patients' elevated levels of Dex..$^{21}$ Preterm labor risk could result from Dex use. ${ }^{22}$ The treatment with Dex (postnatally) is associated with adverse motor outcome, such as abnormal fine 


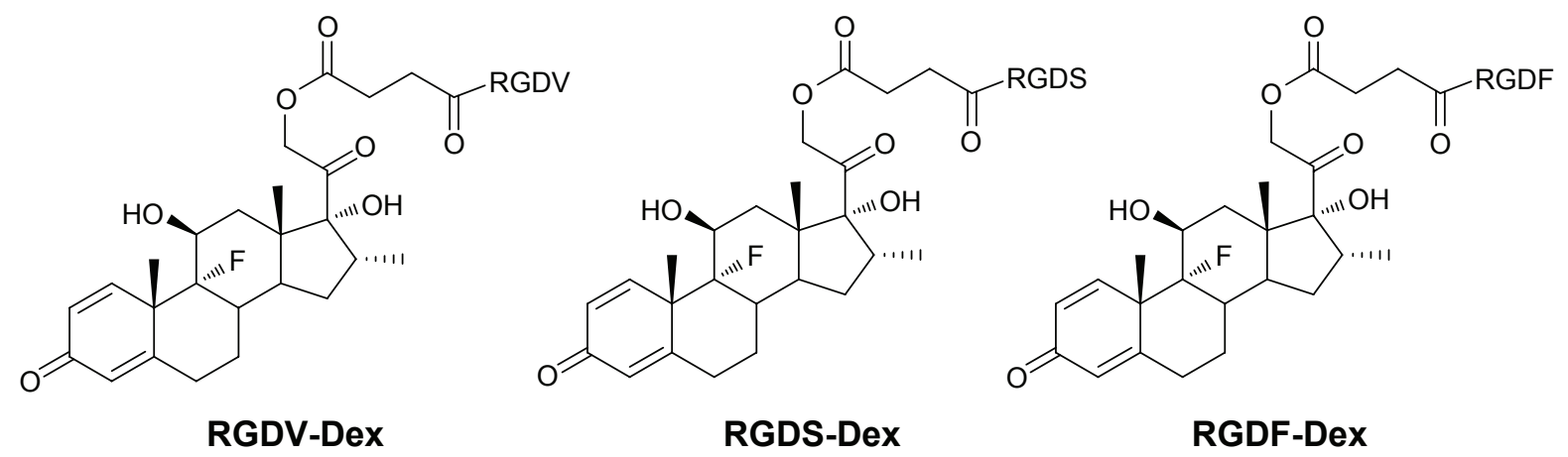

Figure I Structure of RGDV-Dex, RGDS-Dex, and RGDF-Dex.

Abbreviations: RGDV, Arg-Gly-Asp-Val; RGDS, Arg-Gly-Asp-Ser; RGDF, Arg-Gly-Asp-Phe; Dex, dexamethasone.

motor, ball skills and balance, ${ }^{23}$ and ubiquitous distribution is correlated with systemic toxicity. ${ }^{24}$ Dex administration is also the most common cause of secondary osteoporosis. ${ }^{25}$ Therefore, developing safe and effective Dex derivatives is of great clinical importance.

Arg-Gly-Asp-Val (RGDV), Arg-Gly-Asp-Ser (RGDS) and Arg-Gly-Asp-Phe (RGDF) are well-known antiadhesive peptides, which are the motifs of integrins in recognizing collagen, fibronectin, vitronectin, laminin, immunoglobulin superfamily, and plasma proteins. Recently, these peptides were used to modify Dex, yielding three nanoscale conjugates RGDV-Dex, RGDS-Dex, and RGDF-Dex (Figure 1), which are capable of targeting integrins. In a mouse model, the conjugates are superior to Dex in inhibiting inflammatory and osteoporotic actions. ${ }^{26}$ However, whether they are worthy of development remains unclear. In this context, the nanostructures, immunosuppressive activities, thrombosis risks, and toxicities of these three conjugates were investigated.

\section{Materials and methods}

\section{Animals}

Male Wistar rats (male, weighing 250-300 g), BALB/C mice (male, 14 weeks in age), and ICR mice (male, $22 \pm 2 \mathrm{~g}$ ) were purchased from Laboratory Animal Center of Capital Medical University. The animals were housed in polypropylene cages at $22^{\circ} \mathrm{C} \pm 2^{\circ} \mathrm{C}$ and relative humidity of $60 \%-70 \%$, with automatically controlled 12/12 hours light/dark cycle, and provided with the standard pellet diet and drinking water in plastic bottles. All assays were conducted between 9 am and $4 \mathrm{pm}$. Overnight fast was imposed before assays.

Work performed was based on a protocol reviewed and approved by the ethics committee of Capital Medical University. The committee assures that the welfare of the animals was maintained in accordance to the requirements of the Animal Welfare Act and in accordance to the NIH
Guide for Care and Use of Laboratory Animals. Statistical analyses of all the biological data were carried out by use of analysis of variance (ANOVA). $P$-values $<0.05$ were considered statistically significant.

\section{RGDV-Dex, RGDS-Dex, and RGDF-Dex}

Dex was modified with RGD-peptides. In the 9-step modification procedure, the strategy with butane diacid bridging the hydroxy group of Dex at 21-position and the $N$-terminal amino group of the RGD-peptides was used, and three novel conjugates RGDV-Dex, RGDS-Dex, and RGDF-Dex were obtained. The high-performance liquid chromatography (HPLC) purity (CHIRALPAK AH-H column, 4.6×250 mm, Daicel Chemical Industries Ltd., Osaka, Japan) of these conjugates was $97 \%-98 \%$. The chromatograms and the optical spectra are shown in Figures S1-S9.

\section{Transmission electron microscopy}

The examinations of the nanostructures of RGDV-Dex, RGDS-Dex, and RGDF-Dex were performed on a transmission electron microscope (TEM, JSM-6360 LV, JEOL, Tokyo, Japan). The solutions of $10^{-8}, 10^{-10}$, and $10^{-12} \mathrm{M}$ of RGDV-Dex, RGDS-Dex, or RGDF-Dex in water ( $\mathrm{pH}$ 7.0) were dripped onto a formvar coated copper grid, and then a drop of anhydrous ethanol was added to promote the removal of water. At first, the grid was allowed to thoroughly dry in air and then was heated at $37^{\circ} \mathrm{C}$ for 24 hours. The copper grids were viewed under the TEM. The nanostructures were determined from counting over 100 species in randomly selected regions on the copper grids. All determinations were carried out in triplicate grids. The TEM was operated at $80 \mathrm{kV}$, electron beam accelerating voltage. Images were recorded on an imaging plate (Gatan Bioscan Camera model 1792, Gatan, Inc., Pleasanton, CA, USA) with $20 \mathrm{eV}$ energy windows at 6,000-400,000 $\times$ and were digitally enlarged. 


\section{Atomic force microscopy}

To show that our solution was transparent, but not colloidal, we used $10^{-8} \mathrm{M}$ solution, the highest concentration among the three concentrations, to record the atomic force microscopy (AFM) images. AFM tests were performed by using the contact mode on Nanoscope 3D AFM (Veeco Instruments, Ltd, Plainview, NY, USA) under ambient conditions. Samples of rat plasma alone or ultrapure water alone and rat plasma or ultrapure water plus RGDV-Dex, RGDS-Dex, and RGDFDex $\left(10^{-8} \mathrm{M}\right)$ were used for recording the images, and all samples were imaged in triplicate.

\section{Faraday-Tyndall effect test}

The self-assembly property of RGDV-Dex, RGDS-Dex, and RGDF-Dex in aqueous solution was visualized with laser $(650 \mathrm{~nm})$ induced Faraday-Tyndall effect. ${ }^{27}$ For this purpose, $\mathrm{pH} 7.0$ ultrapure water and $\mathrm{pH} 2.0$ ultrapure water were irradiated with laser beam of $650 \mathrm{~nm}$, and Faraday-Tyndall effect was recorded. Similarly, the $10^{-8} \mathrm{M}$ solution of RGDV-Dex or RGDS-Dex or RGDF-Dex in ultrapure water ( $\mathrm{pH} 7.0$ and $\mathrm{pH} 2.0$ ) was irradiated with laser beam of $650 \mathrm{~nm}$ and Faraday-Tyndall effect was recorded.

\section{Size distribution test}

After 7-day storage at room temperature, size distribution test of the $10^{-8} \mathrm{M}$ solutions of RGDV-Dex or RGDS-Dex or RGDF-Dex in ultrapure water $(\mathrm{pH} 7.0$ and $\mathrm{pH} 2.0$ ) was carried out on a Malvern Zetasizer (Nano-ZS90; Malvern Instruments, Malvern, UK) with the DTS (Nano) Program.

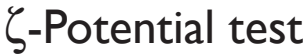

Seven days after room temperature storage, the $\zeta$-potential of $10^{-8} \mathrm{M}$ solution of RGDV-Dex or RGDS-Dex or RGDF-Dex in ultrapure water $(\mathrm{pH} 7.0)$ was measured using the automatic mode on a Malvern's Zetasizer (Nano-ZS90; Malvern Instruments) with the DTS (Nano) Program.

\section{Concanavalin A-induced lymphocyte proliferation assay}

BALB/C mouse was killed, the spleen was extirpated in asepsis condition, triturated with injector core on stainless steel mesh of 200 , washed with PBS $(0.5 \mathrm{~mL} \times 2)$, at $1,500 \mathrm{rpm} / \mathrm{min}$ centrifuged for 10 minutes suspended in Roswell Park Memorial Institute-1640 medium to form $5 \times 10^{6}$ cells $/ \mathrm{mL}$ suspension. To each well of the $96-$ well microplate, $100 \mu \mathrm{L}$ cell suspension and $20 \mu \mathrm{L}$ concanavalin A (ConA, final concentration, $5 \mu \mathrm{g} / \mathrm{mL}$ ) were successively added, the 96-well microplate was cultured at $37^{\circ} \mathrm{C}$ in a humidified atmosphere of $5 \% \mathrm{CO}_{2}$ for 4 hours. ConA induced proliferation of spleen lymphocytes of BALB/C mice was measured. Based on the tested optical density $(\mathrm{OD})$ and $\%$ inhibition $=\left[\left(\mathrm{OD}_{4 \mathrm{a}-\mathrm{c}}-\mathrm{OD}_{\mathrm{ConA}}\right) / \mathrm{OD}_{\mathrm{ConA}}\right] \times 100 \%$ (where in $\mathrm{OD}_{4 \mathrm{a}-\mathrm{c}}$ represents the $\mathrm{OD}$ value derived from the lymphocytes treated with RGDV-Dex, or RGDS-Dex, or RGDF-Dex, $\mathrm{OD}_{\mathrm{ConA}}$ represents the OD value derived from the lymphocytes treated with ConA), the inhibitory rates of RGDV-Dex, or RGDS-Dex, or RGDF-Dex were calculated, of which the inhibitions at various concentrations $\left(1 \times 10^{-4}\right.$, $8 \times 10^{-5}, 5 \times 10^{-5}, 2 \times 10^{-5}, 1 \times 10^{-5}, 8 \times 10^{-6}, 5 \times 10^{-6}$, and $1 \times 10^{-6}$ M) were calculated to draw the proliferation curve of mouse spleen cells and to calculate the half-maximal inhibitory concentration $\left(\mathrm{IC}_{50}\right)$ values.

\section{Myocardium survival time assay}

The split hearts $(3 \times 3 \mathrm{~mm}$ in size) were prepared with the hearts of $\mathrm{C} 57 \mathrm{bl} / 6$ mice of near full term fetuses to 48 hours old and transplanted into the base of the "pocket" near the distal edge of the ear of BALB/C mice (male, 14 weeks in age) by following the standard procedure. One day after transplantation, the mice in positive control group were intraperitoneally injected the suspension of cyclosporine A (CsA) in $0.5 \%$ carmellose sodium (CMCNa, $2.5 \mu \mathrm{mol} / \mathrm{kg} / \mathrm{d}$ ), the mice in negative control group were orally given $0.2 \mathrm{~mL}$ of $0.5 \% \mathrm{CMCNa} /$ mouse/d, the mice in RGDV-Dex or RGDSDex treated groups were orally given the suspensions of the respective drugs in $0.5 \% \mathrm{CMCNa}(1.43 \mu \mathrm{mol} / \mathrm{kg} / \mathrm{d})$, the mice in RGDF-Dex treated groups were orally given the suspension of the drug in $0.5 \%$ carmellose sodium $(\mathrm{CMCNa}, 1.43$, 0.143 , and $0.0143 \mu \mathrm{mol} / \mathrm{kg} / \mathrm{d}$ ), and the treatment was continued for 15 days. From seventh day, the split hearts implanted near the distal edge of the mouse ear received cardiogram examination every day to monitor their survival.

\section{In vivo antithrombotic assay}

Wistar rats were used in this assay. CMCNa (negative control) or aspirin (positive control) or RGDV-Dex or RGDS-Dex or RGDF-Dex suspended in CMCNa before administration was kept in an ice bath. Thirty minutes after the oral administration of $3 \mathrm{~mL} / \mathrm{kg}$ of CMCNa or $3 \mathrm{~mL} / \mathrm{kg}$ of aspirin (Beijing Pharmaceutical Works, Beijing, People's Republic of China) in $\mathrm{CMCNa}(167 \mu \mathrm{mol} / \mathrm{kg}, 16.7 \mu \mathrm{mol} / \mathrm{kg})$, or $3 \mathrm{~mL} / \mathrm{kg}$ of RGDV-Dex in CMCNa $(1.43 \mu \mathrm{mol} / \mathrm{kg})$ or $3 \mathrm{~mL} / \mathrm{kg}$ of RGDSDex in CMCNa $(1.43 \mu \mathrm{mol} / \mathrm{kg})$, or $3 \mathrm{~mL} / \mathrm{kg}$ of RGDF-Dex in $\mathrm{CMCNa}(1.43 \mu \mathrm{mol} / \mathrm{kg})$ the rats were anesthetized with pentobarbital sodium (Beijing Pharmaceutical Works, $80.0 \mathrm{mg} / \mathrm{kg}$, 
intraperitoneal injection) and the right carotid artery and left jugular vein were separated. A weighed $6 \mathrm{~cm}$ thread was inserted into the middle of a polyethylene tube which was filled with heparin sodium (50 IU/mL in normal saline). One end of the polyethylene tube was inserted into the left jugular vein. From the other end of the polyethylene tube, heparin sodium was injected as anticoagulant, and this end was inserted into the right carotid artery. Blood was allowed to flow from the right carotid artery to the left jugular vein through the polyethylene tube for 15 minutes. The thread was retrieved to obtain the thrombus weight. After operation, the treated rats were euthanized immediately by exsanguination from the right carotid artery under pentobarbital sodium anesthesia.

\section{In vivo tail bleeding time assay}

The assay was performed by following a standard procedure. In brief, male ICR mice (18-22 g) were orally administered with $\mathrm{CMCNa}(0.5 \%, 0.2 \mathrm{~mL} / \mathrm{mouse}$ of dose $)$ or the suspension of Dex in CMCNa (dose, $2.5 \mu \mathrm{mol} / \mathrm{kg}$ ), and orally administered with the suspension of RGDF-Dex or RGDSDex or RGDV-Dex in CMCNa (dose, $1.43 \mu \mathrm{mol} / \mathrm{kg}$ ). Thirty minutes after the administration, the mouse was placed in a tube holder, the tail of the mouse was protruded, and $2 \mathrm{~mm}$ of tail tine was cut off. The flowing blood was gently wiped away with a filter paper every 30 seconds until blood flow stopped; this helped calculate the bleeding time.

\section{Acute toxicity assay}

Male ICR mice were purchased from Laboratory Animal Center of Capital Medical University for determining acute toxicity. The mice were maintained at $21^{\circ} \mathrm{C}$ with a natural day/night cycle in a conventional animal colony and were 10 weeks old at the beginning of the experiment. Twelve hours after fasting, mice were randomly divided into eight groups (six per group). The mice were orally administered with the suspension of RGDV-Dex or RGDSDex or RGDF-Dex in CMCNa (dose: $14.3 \mu \mathrm{mol} / \mathrm{kg}, 100$ times of $0.143 \mu \mathrm{mol} / \mathrm{kg}$ of the minimal effective dose) or CMCNa $(0.5 \%, 0.2 \mathrm{~mL} / \mathrm{mouse})$. Four hours or 7 days after the administration, the mice received ether anesthesia and were sacrificed to sample the blood and organs for toxic analysis.

\section{Determination of serum ALT, AST, and $\mathrm{Cr}$}

To estimate the effect of RGDV-Dex, or RGDS-Dex, or RGDF-Dex on liver and kidney function, acute toxicity assay was performed on the blood of ICR mice and the blood was centrifuged to obtain serum for measuring alanine transaminase (ALT), aspartate transaminase (AST), and creatinine
(Cr) by using alanine aminotransferase assay kit, aspartate aminotransferase assay kit, and creatinine assay kit, respectively, on a microtiter plate reader within 15 minutes and recording OD value. All kits were purchased from Nanjing Jiancheng Bioengineering Institute. According to the standard curve, the serum concentrations of ALT, AST, and $\mathrm{Cr}$ were calculated $(n=12)$. Data were statistically analyzed by Student's $t$-test. $P$-values $<0.05$ were considered statistically significant.

\section{Results}

\section{Concentration and structure-dependent TEM images}

In order to examine the effect of the concentration on the nanofeature, the TEM images of $10^{-8}, 10^{-10}$, and $10^{-12} \mathrm{M}$ of RGDV-Dex, RGDS-Dex, and RGDF-Dex in ultrapure water ( $\mathrm{pH} 7.0$ ) were recorded and are shown in Figure 2. The nanoparticle diameters of $10^{-8}, 10^{-10}$, and $10^{-12} \mathrm{M}$ of RGDF-Dex are 35-121, 25-75, and 23-85 $\mathrm{nm}$, respectively. The nanoparticle diameters of $10^{-8}, 10^{-10}$, and $10^{-12} \mathrm{M}$ of RGDS-Dex are 23-186, 18-92, and 14-123 nm, respectively. The nanoparticle diameters of $10^{-8}, 10^{-10}$, and $10^{-12} \mathrm{M}$ of RGDV-Dex are 33-250, 11-254, and 26-103 nm, respectively. The diameter of the nanoparticles is decided by both concentration and the sequence of RGD-peptides.

\section{Rat plasma and water do not affect the AFM image}

To examine nanofeature of the conjugates in blood, the AFM images of $10^{-8} \mathrm{M}$ of RGDV-Dex, RGDS-Dex, and RGDF-Dex in rat plasma were recorded and are shown in Figure 3A-D. As seen, in rat plasma RGDF-Dex, RGDS-Dex, and RGDV-Dex form the nanoparticles of $\sim 101, \sim 163$, and $\sim 160 \mathrm{~nm}$ in size, respectively, while rat plasma alone does not give any comparable nanoparticles. Of three conjugates, RGDF-Dex forms the smallest nanoparticles.

To exclude the effect of TEM and AFM models on the nanoparticle size, the AFM images of RGDV-Dex, RGDSDex, and RGDF-Dex in ultrapure water $\left(10^{-8} \mathrm{M}\right)$ were also recorded and are shown in Figure 3E-H. As seen in both rat plasma and ultrapure water, $10^{-8} \mathrm{M}$ of RGDV-Dex, RGDSDex, and RGDF-Dex form similar nanoparticles.

\section{The aqueous solution of the conjugates show nanoproperty}

To show that the aqueous solution of the conjugates has nanoproperty, Faraday-Tyndall effect, size distribution, and $\zeta$-potential tests were carried out in the $10^{-8} \mathrm{M}$ solution of 


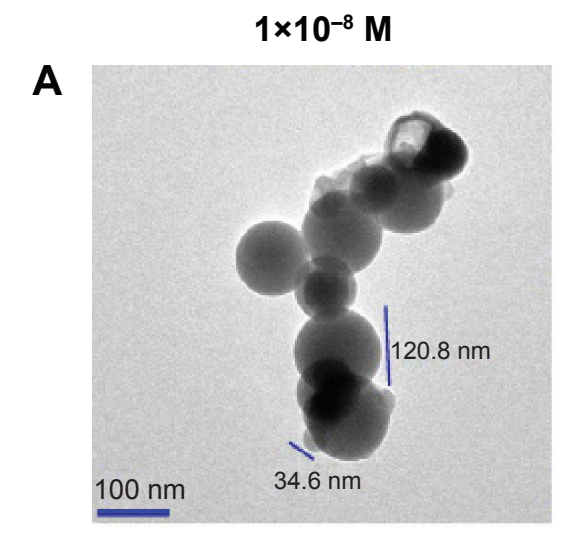

B
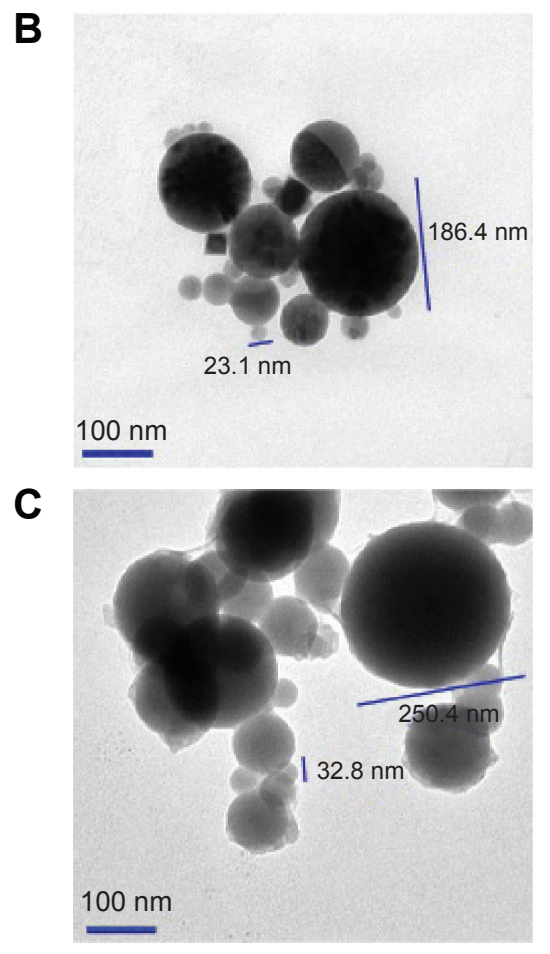

$1 \times 10^{-10} M$
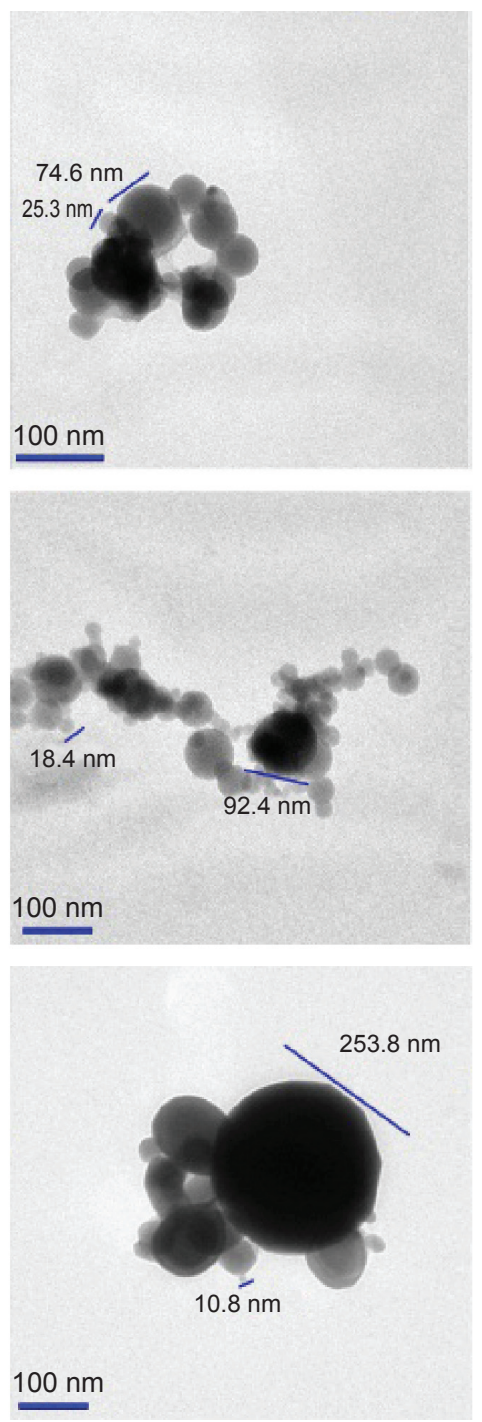

$1 \times 10^{-12} \mathrm{M}$
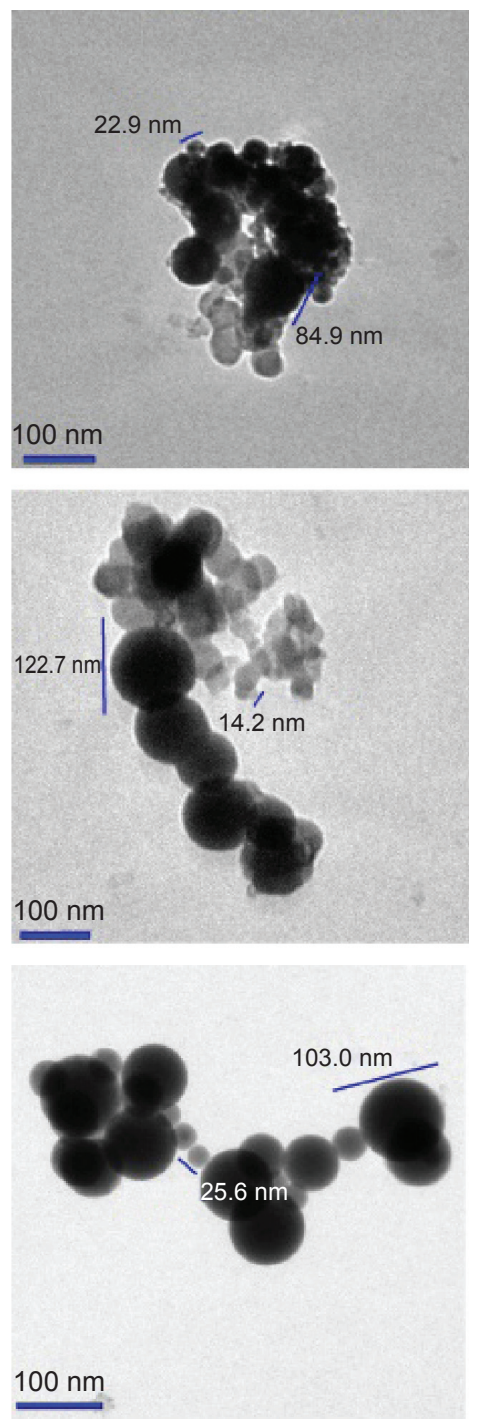

Figure 2 TEM images showing the effects of concentration.

Notes: (A) TEM images of $10^{-8}, 10^{-10}$, and $10^{-12} \mathrm{M}$ of RGDF-Dex in ultrapure water ( $\mathrm{pH} 7.0$ ); (B) TEM images of $10^{-8}$, $10^{-10}$, and $10^{-12} \mathrm{M}$ of RGDS-Dex in ultrapure water ( $\mathrm{pH} 7.0)$; (C) TEM images of $10^{-8}, 10^{-10}$, and $10^{-12} \mathrm{M}$ of RGDV-Dex in ultrapure water ( $\left.\mathrm{pH} 7.0\right)$.

Abbreviations: TEM, transmission electron microscope; RGDF, Arg-Gly-Asp-Phe; RGDS, Arg-Gly-Asp-Ser; RGDV, Arg-Gly-Asp-Val; Dex, dexamethasone.

RGDF-Dex, RGDS-Dex, and RGDV-Dex in ultrapure water. Figure 4A-D indicate that similar to ultrapure water, without laser beam irradiation the solutions of RGDF-Dex, RGDSDex, and RGDV-Dex in ultrapure water are clean, while the irradiation of $650 \mathrm{~nm}$ laser beam induces the solutions of the conjugates in $\mathrm{pH} 7.0$ and $\mathrm{pH} 2.0$ ultrapure water to show Faraday-Tyndall effect.

The $10^{-8} \mathrm{M}$ of conjugate aqueous solutions were also tested on a Malvern's Zetasizer (Nano-ZS90; Malvern Instruments) with the DTS (Nano) Program to characterize the size distribution. Figure $4 \mathrm{E}-\mathrm{G}$ indicate that the sizes of RGDF-Dex, RGDS-Dex, and RGDV-Dex in pH 2.0 and 7.0 ultrapure water are $276.1 \pm 37.7$ and $268.9 \pm 39.3$, $263.9 \pm 86.2$, and $302.0 \pm 76.7 \mathrm{~nm}$ as well as $263.9 \pm 86.2$ and
$258.4 \pm 81.6 \mathrm{~nm}$, respectively. The size distribution of the conjugates in $\mathrm{pH} 7.0$ ultrapure water is less than that in $\mathrm{pH} 2.0$ ultrapure water.

$\zeta$-Potential tests were measured in the $10^{-8} \mathrm{M}$ conjugate aqueous solutions . Figure $4 \mathrm{H}-\mathrm{J}$ indicate that the $\zeta$-potentials of RGDF-Dex, RGDS-Dex, and RGDV-Dex in pH 7.0 ultrapure water are $39.3,31.5$, and $11.9 \mathrm{mV}$, respectively; RGDF-Dex possesses the highest value.

\section{The conjugates inhibit spleen lymphocytes' proliferation}

The immunosuppressive activities of the conjugates were evaluated by ConA-induced proliferation of BALB/c mouse spleen lymphocytes. Figure 5 indicates that the $\mathrm{IC}_{50}$ values 


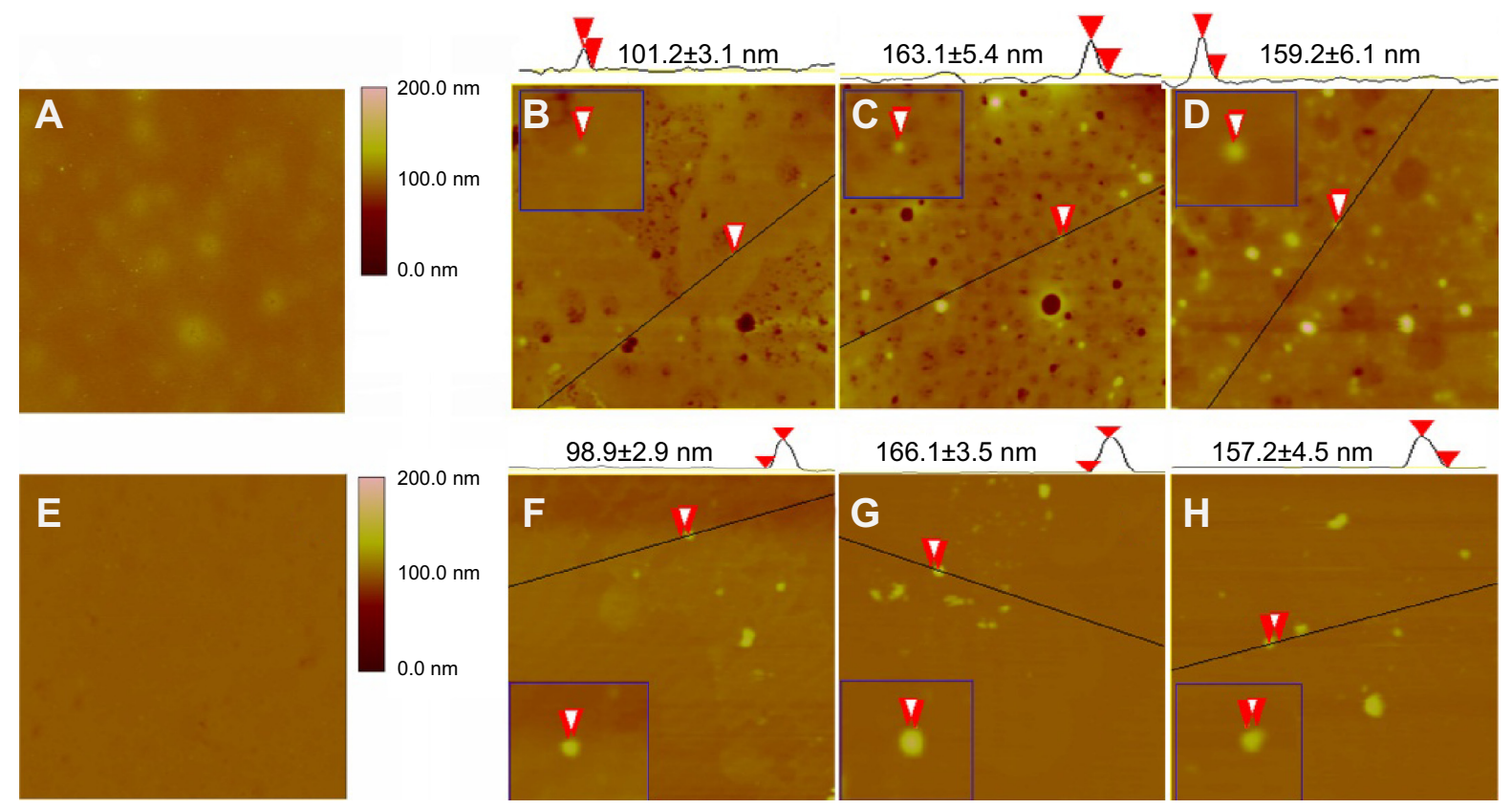

Figure 3 AFM images.

Notes: (A) AFM images of rat plasma alone; (B) AFM images of $10^{-8} \mathrm{M}$ of RGDF-Dex in rat plasma; (C) AFM images of $10^{-8} \mathrm{M}$ of RGDS-Dex in rat plasma; (D) AFM images of $10^{-8} \mathrm{M}$ of RGDV-Dex in rat plasma; (E) AFM images of ultrapure water alone; (F) AFM images of $10^{-8} \mathrm{M}$ of RGDF-Dex in ultrapure water; (G) AFM images of I0-8 $\mathrm{M}$ of RGDS-Dex in ultrapure water; $(\mathbf{H})$ AFM images of $10^{-8} \mathrm{M}$ of RGDV-Dex in ultrapure water. Inset in each figure shows magnified area identified by the red triangles.

Abbreviations: AFM, atomic force microscopy; RGDF, Arg-Gly-Asp-Phe; RGDS, Arg-Gly-Asp-Ser; RGDV, Arg-Gly-Asp-Val; Dex, dexamethasone.

of Dex, RGDV-Dex, RGDS-Dex, and RGDF-Dex against spleen lymphocyte proliferation are $0.223,0.133,0.136$, and $0.031 \mu \mathrm{M}$, respectively. The $\mathrm{IC}_{50}$ values of RGDV-Dex and RGDS-Dex are significantly lower than that of Dex, but significantly higher than that of RGDF-Dex. Thus, RGDF-Dex possesses the highest inhibition on the spleen lymphocyte proliferation of $\mathrm{BALB} / \mathrm{C}$ mice in vitro.

\section{The conjugates prolong survival time of the implanted myocardium}

The immunosuppressive activities of the conjugates were also evaluated by survival time of the myocardium implanted in $\mathrm{BALB} / \mathrm{C}$. The mice were treated with oral $\mathrm{CMCNa}$ ( $0.5 \%$, negative control), or intraperitoneal CsA (positive control, $2.5 \mu \mathrm{mol} / \mathrm{kg} / \mathrm{d}$ ), or oral Dex (reference control, $2.5 \mu \mathrm{mol} / \mathrm{kg} / \mathrm{d})$, or oral conjugate $(1.43 \mu \mathrm{mol} / \mathrm{kg} / \mathrm{d})$ for 15 days. Figure 6 indicates that compared to the survival time of the myocardium implanted in the mice treated with CMCNa (9.6 days), those treated with CsA (12.0 days) and Dex (11.7 days) led to the increase of survival time by 2.4 and 2.1 days, respectively. Comparing the survival time of the myocardium implanted in the mice treated with Dex, treating with RGDV-Dex (13.4 days), RGDS-Dex (13.7 days), and RGDF-Dex (13.8 days) led to the increase of survival time by $1.7,2.0$, and 2.1 days, respectively. The myocardium implanted in the mice treated with RGDF-Dex exhibits the longest survival time. Thus, the dose-dependent action of RGDF-Dex was tested. Figure 6 indicates that the survival time of the myocardium implanted in the mice treated with $1.43,0.143$, and $0.0143 \mu \mathrm{mol} / \mathrm{kg} / \mathrm{d}$ of RGDF-Dex is 13.8 , 12.3, and 9.9 days, respectively, suggesting that RGDF-Dex dose-dependently increases the survival time.

\section{The conjugates induce no coagulation risk}

The tail bleeding time assay was used to evaluate the coagulation risk of the conjugates. Figure 7 indicates that the tail bleeding time of the mice treated with Dex $(1.43 \mu \mathrm{mol} / \mathrm{kg}$ of dose) is significantly shorter than that of the mice treated with CMCNa. In contrast, $1.43 \mu \mathrm{mol} / \mathrm{kg}$ of RGDF-Dex, RGDS-Dex, and RGDV-Dex do not alter the tail bleeding time of CMCNa treated mice.

\section{The conjugates have antithrombotic action}

The antithrombotic activities of the conjugates were evaluated with rat thrombosis assay and represented as thrombus weight. In the assay, the rats were orally given $\mathrm{CMCNa}(0.5 \%$, negative control) or the suspension of aspirin in $\mathrm{CMCNa}$ (positive control, 167 and $16.7 \mu \mathrm{mol} / \mathrm{kg}$ ), or the suspension 


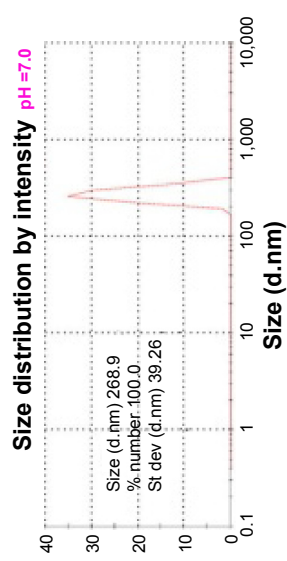

(\%) К!

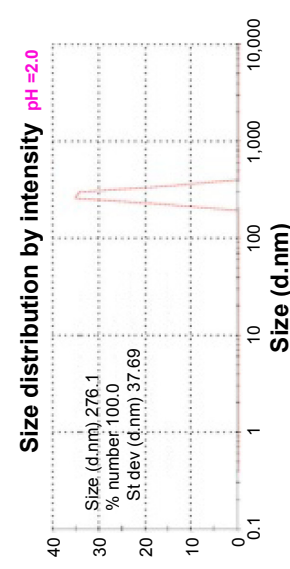

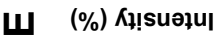

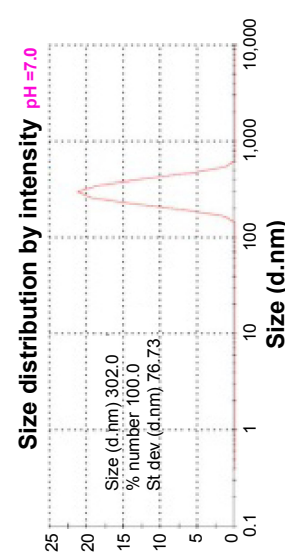

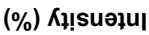

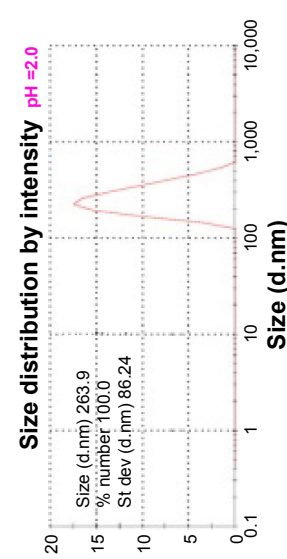

L. (\%) Kł!suəłu|
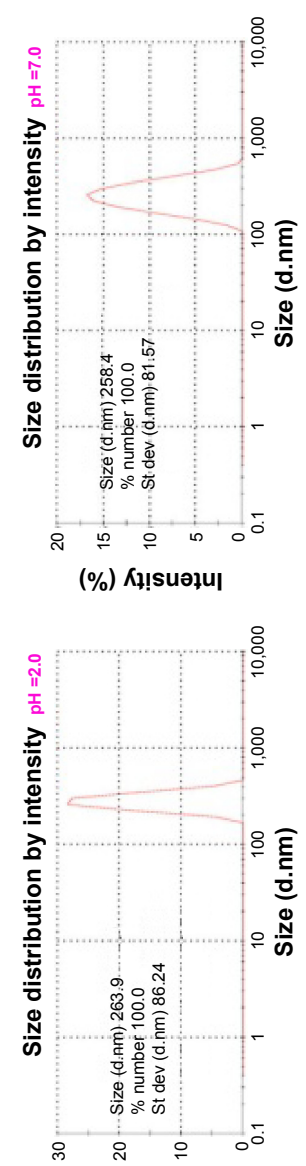

(1) (\%) К! suәəu|
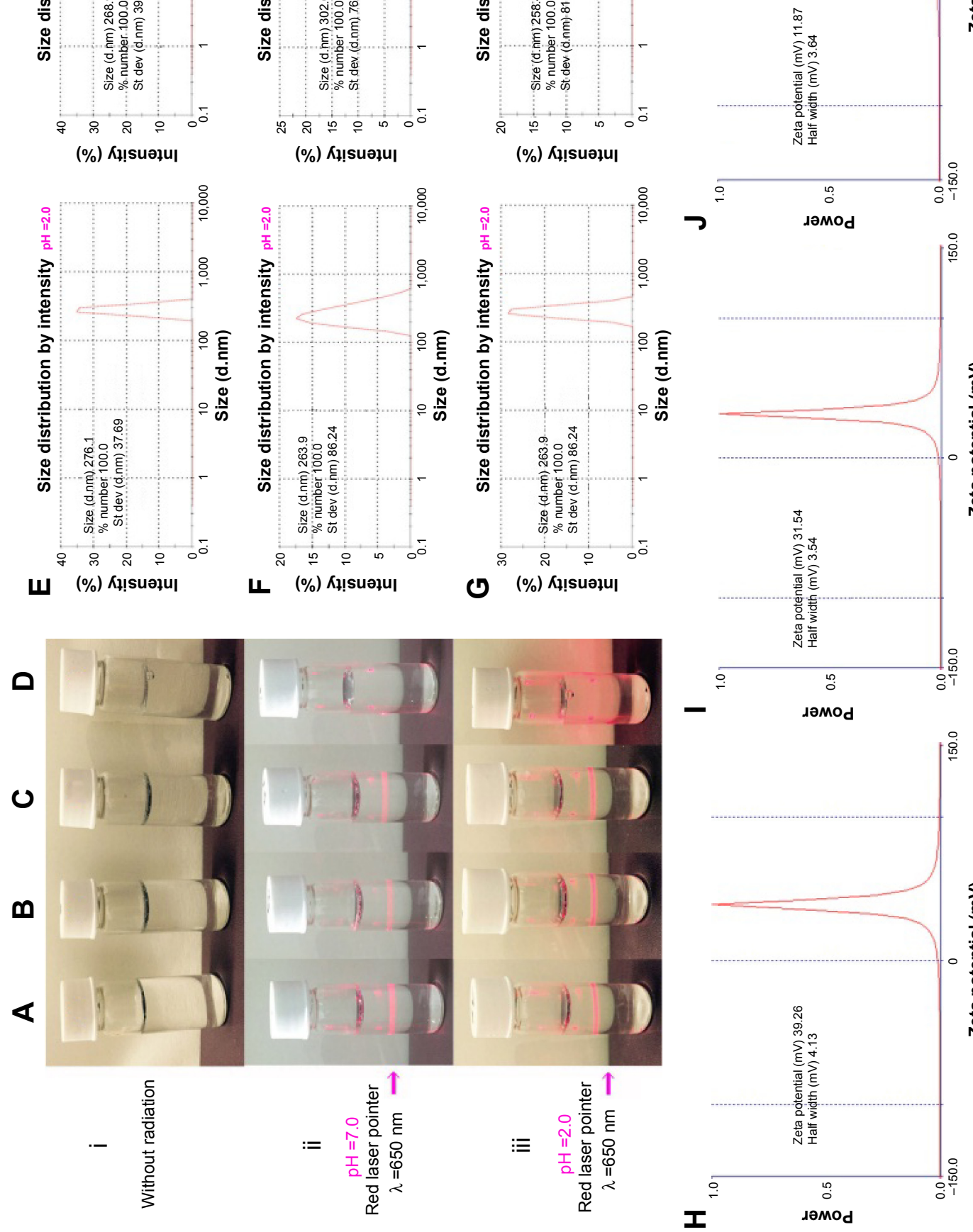

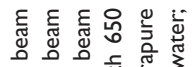

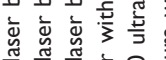

ह

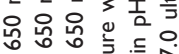

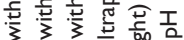

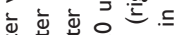

3

\&

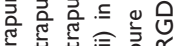

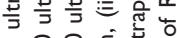

엇어엉 흔 흔

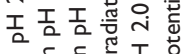

$\subseteq \subseteq . \leqq$ I

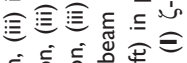

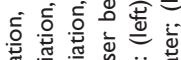

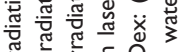

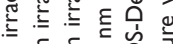

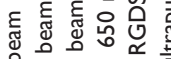

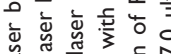

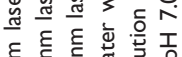

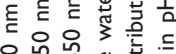

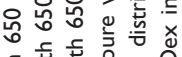

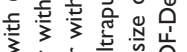

离离离芹芹包

उुड $3 \pi$

을 논

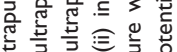

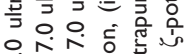

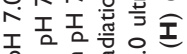

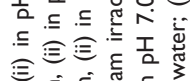

ㅎํ웛 $\cong$

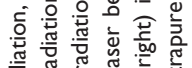

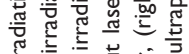

迎.

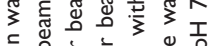

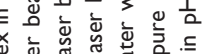

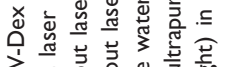

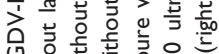

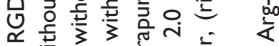

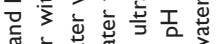

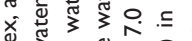

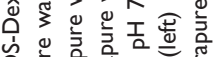

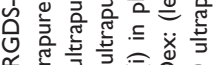

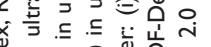

ร

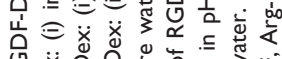

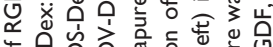

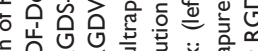

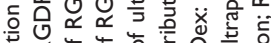

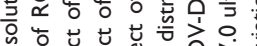

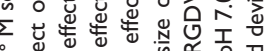

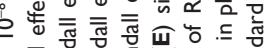

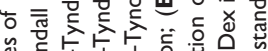

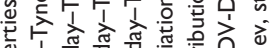

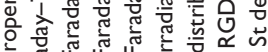

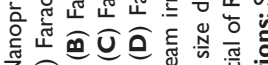

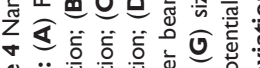

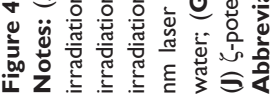




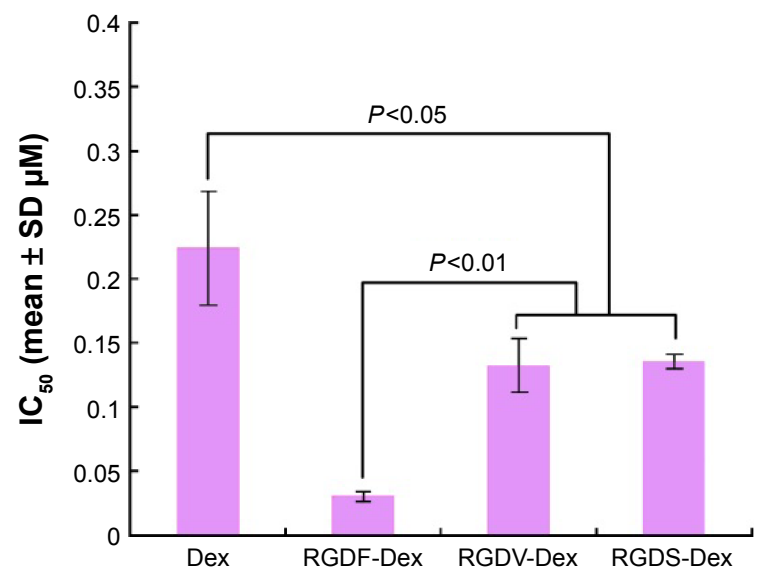

Figure $\mathbf{5}$ The effect of RGDV-Dex, RGDS-Dex, and RGDF-Dex on ConA-induced proliferation of the spleen lymphocytes of BALB/C mouse, $n=3$.

Abbreviations: Dex, dexamethasone; RGDF, Arg-Gly-Asp-Phe; RGDS, Arg-GlyAsp-Ser; RGDV, Arg-Gly-Asp-Val; ConA, concanavalin; $I C_{50}$, half maximal inhibitory concentration; SD, standard deviation.

of Dex in CMCNa $(1.43 \mu \mathrm{mol} / \mathrm{kg}$ dose $)$, or the suspension of the conjugate in $\mathrm{CMCNa}(1.43 \mu \mathrm{mol} / \mathrm{kg}$ dose $)$. Figure 8 indicates that the thrombus weight of Dex treated rats is equal to that of CMCNa- or $16.7 \mu \mathrm{mol} / \mathrm{kg}$ aspirin-treated rats. The thrombus weights of RGDV-Dex-, RGDS-Dex-, and RGDF-Dex-treated rats are significantly lower than that of $\mathrm{CMCNa}$ treated rats.

\section{The conjugates do not slow mouse growth}

The toxic reaction of the conjugates was mirrored by the body weight of the treated BALB/C mice. Figure 9 indicates that 15 days after the treatment, the body weight of the mice treated with $2.5 \mu \mathrm{mol} / \mathrm{kg} / \mathrm{d}$ of Dex is significantly lower than

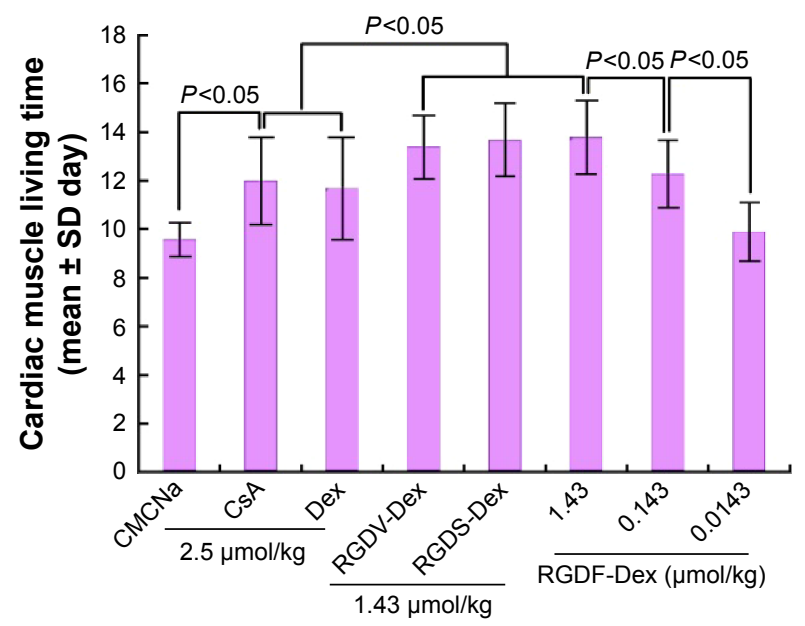

Figure 6 The survival time of the implanted myocardium in the "pocket" near the distal edge of the ear of BALB/C mice, $n=12$.

Abbreviations: Dex, dexamethasone; CMCNa, carmellose sodium; RGDV, ArgGly-Asp-Val; RGDF, Arg-Gly-Asp-Phe; RGDS, Arg-Gly-Asp-Ser; CsA, cyclosporine A; $\mathrm{SD}$, standard deviation.

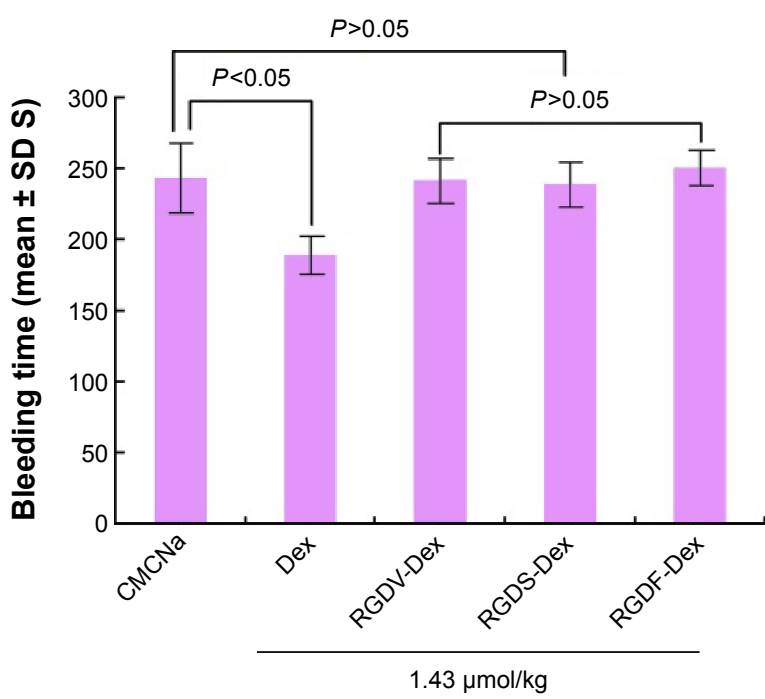

Figure 7 Tail bleeding time of RGDV-Dex-, RGDS-Dex-, and RGDF-Dex-treated mice, $n=12$.

Abbreviations: CMCNa, carmellose sodium; Dex, dexamethasone; RGDV, ArgGly-Asp-Val; RGDF, Arg-Gly-Asp-Phe; RGDS, Arg-Gly-Asp-Ser; SD, standard deviation.

that of the mice treated with $1.43 \mu \mathrm{mol} / \mathrm{kg} / \mathrm{d}$ of RGDV-Dex, RGDS-Dex, or RGDF-Dex.

The toxic reaction of the conjugates was also mirrored with the spleen index (spleen weight/body weight) of the BALB/C mice. Figure 10 indicates that 15 days after the treatment, the spleen index of the mice treated with $2.5 \mu \mathrm{mol} / \mathrm{kg} / \mathrm{d}$ of Dex is significantly lower than that of the mice treated with $1.43 \mu \mathrm{mol} / \mathrm{kg} / \mathrm{d}$ of RGDV-Dex, RGDS-Dex, or RGDF-Dex.

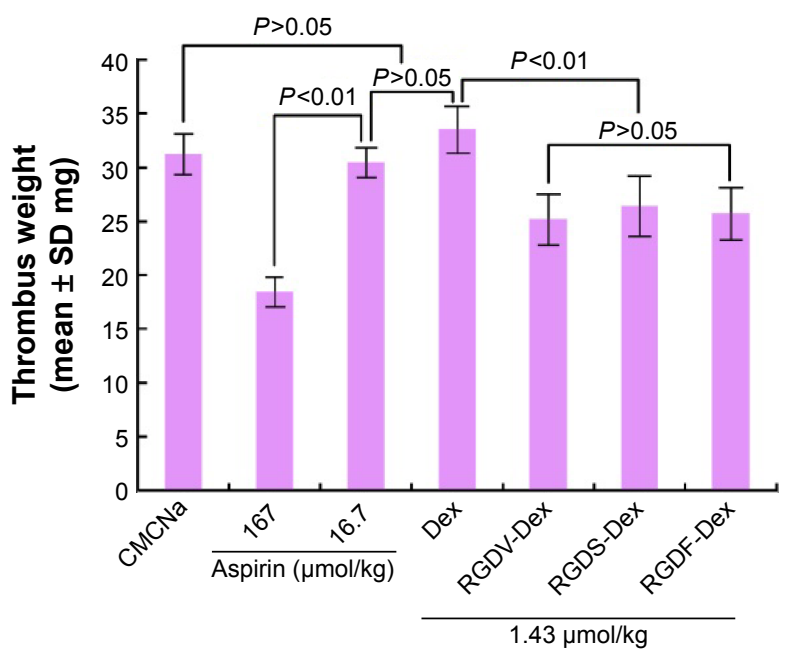

Figure 8 Anti-thrombotic activities of Dex, RGDV-Dex, RGDS-Dex, and RGDFDex, $n=12$.

Abbreviations: CMCNa, carmellose sodium; Dex, dexamethasone; RGDV, ArgGly-Asp-Val; RGDF, Arg-Gly-Asp-Phe; RGDS, Arg-Gly-Asp-Ser; SD, standard deviation. 


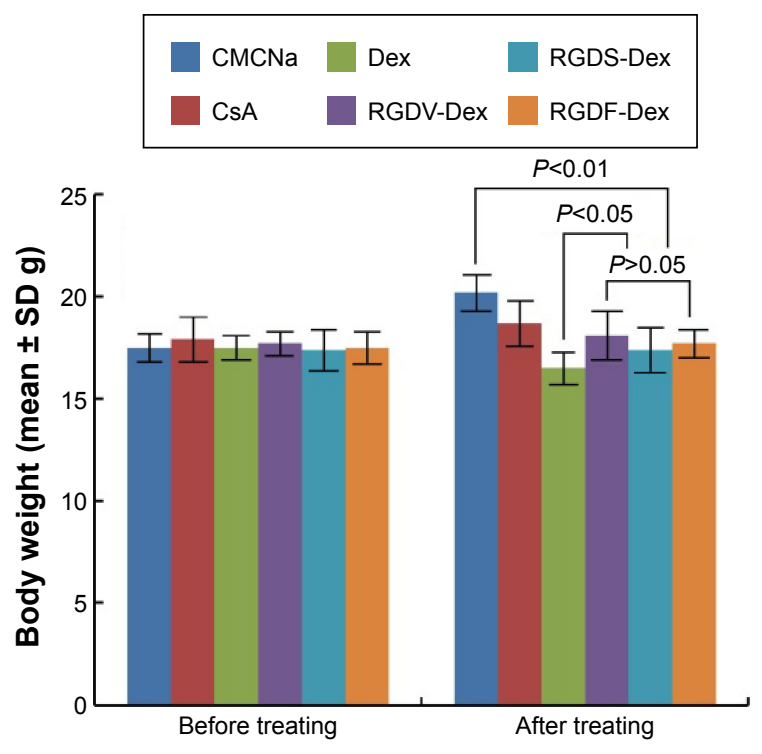

Figure 9 Body weight of the treated BALB/C mice, $n=12$.

Abbreviations: Dex, dexamethasone; CMCNa, carmellose sodium; RGDV, ArgGly-Asp-Val; RGDF, Arg-Gly-Asp-Phe; RGDS, Arg-Gly-Asp-Ser; CsA, cyclosporine A; $\mathrm{SD}$, standard deviation.

The toxic reaction of the conjugates was further mirrored with the liver index (liver weight/body weight) of the BALB/C mice. Figure 11 shows that 15 days after the treatment, the liver index of the mice treated with $2.5 \mu \mathrm{mol} / \mathrm{kg} / \mathrm{d}$ of Dex is significantly lower than that of the mice treated with $1.43 \mu \mathrm{mol} /$ $\mathrm{kg}$ /d of RGDV-Dex, RGDS-Dex, and RGDF-Dex.

\section{The conjugates do not induce acute toxicity}

Acute toxicity assay was carried out in the healthy ICR mice by orally treating with the conjugates at a single dose

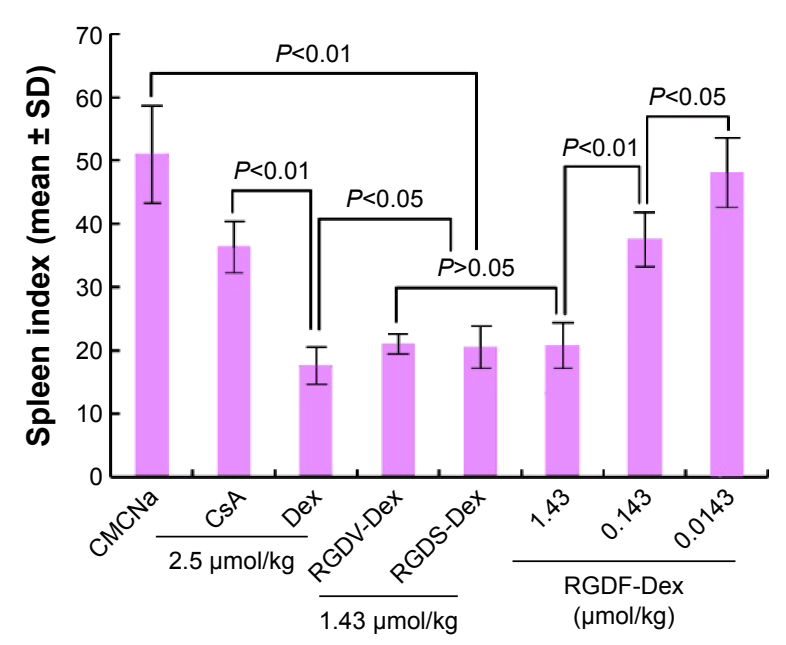

Figure 10 Spleen index of the treated BALB/C mice, $n=12$.

Abbreviations: Dex, dexamethasone; CMCNa, carmellose sodium; RGDV, ArgGly-Asp-Val; RGDF, Arg-Gly-Asp-Phe; RGDS, Arg-Gly-Asp-Ser; CsA, cyclosporine A; $\mathrm{SD}$, standard deviation.

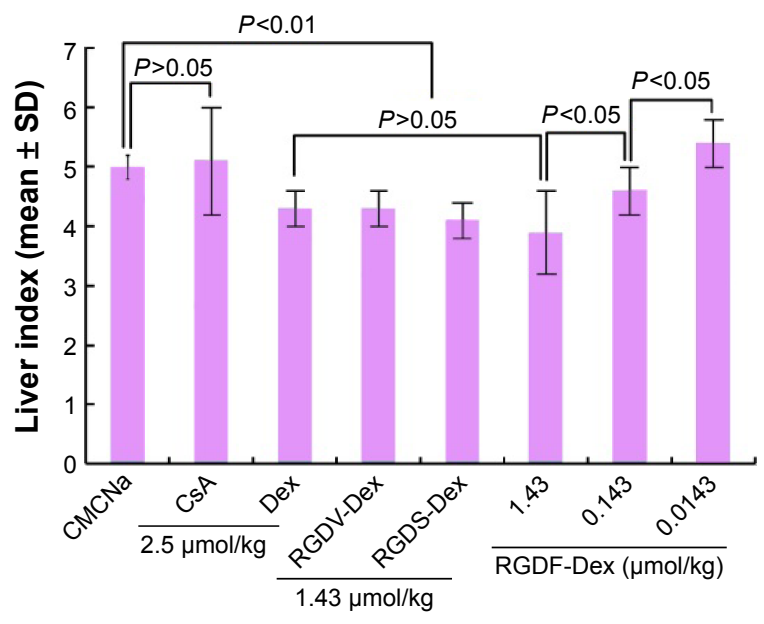

Figure I I Liver index of the treated BALB/C mice, $n=12$.

Abbreviations: Dex, dexamethasone; CMCNa, carmellose sodium; RGDV, ArgGly-Asp-Val; RGDF, Arg-Gly-Asp-Phe; RGDS, Arg-Gly-Asp-Ser; CsA, cyclosporine A; $\mathrm{SD}$, standard deviation.

of $14.3 \mu \mathrm{mol} / \mathrm{kg}$, a dose of 100 times of the minimal effective dose $0.143 \mu \mathrm{mol} / \mathrm{kg}$, and the mice were monitored for 7 days. It was found that during 7 days, the mice had no abnormal behavior, while the autopsy showed no morphological changes in the organs. Serum ALT, AST, and Cr of the mice were determined by the kits. Figures 12-14 show that the serum ALT, AST, and Cr of the mice treated with $14.3 \mu \mathrm{mol} / \mathrm{kg}$ RGDV-Dex or RGDS-Dex or RGDF-Dex have normal values.

\section{Discussion}

Dex is the most effective anti-inflammatory glucocorticoid in treating several chronic and acute inflammatory conditions, ${ }^{1-5}$

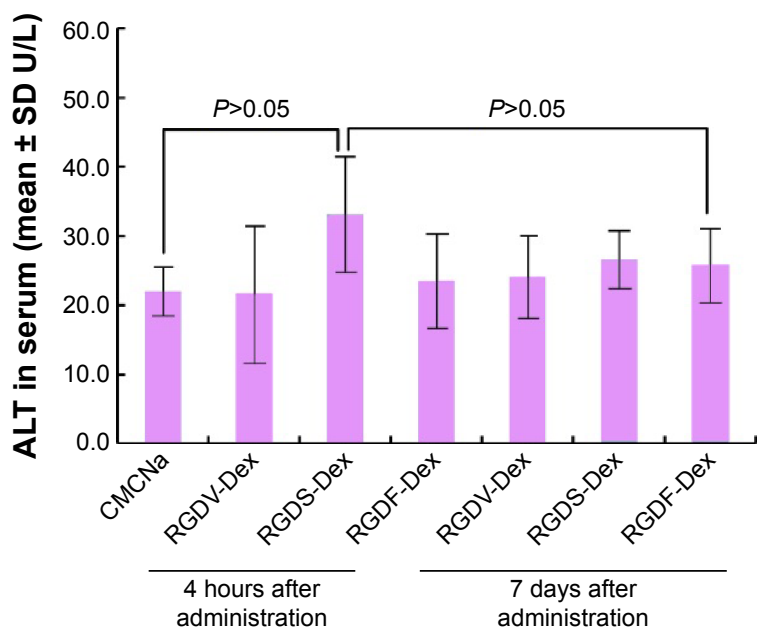

Figure 12 Serum ALT levels of the mice on which acute toxicity assay was performed, $n=12$.

Abbreviations: ALT, alanine transaminase; CMCNa, carmellose sodium; Dex, dexamethasone; RGDV, Arg-Gly-Asp-Val; RGDF, Arg-Gly-Asp-Phe; RGDS, ArgGly-Asp-Ser; SD, standard deviation. 


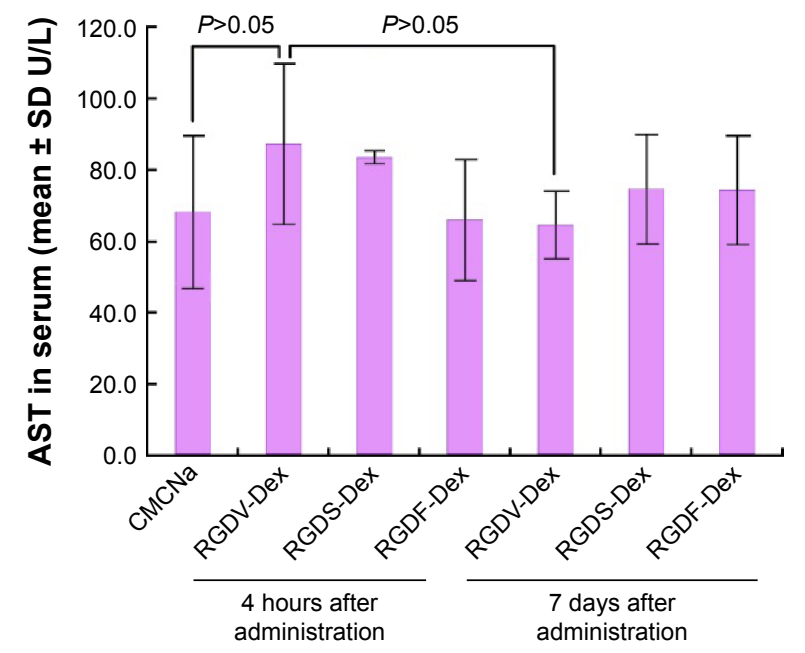

Figure 13 AST levels of the mice on which acute toxicity assay was performed, $\mathrm{n}=12$.

Abbreviations: AST, aspartate transaminase; CMCNa, carmellose sodium; Dex, dexamethasone; RGDV, Arg-Gly-Asp-Val; RGDF, Arg-Gly-Asp-Phe; RGDS, ArgGly-Asp-Ser; SD, standard deviation.

preventing rejection of the transplanted organ, and preserving graft function. ${ }^{15,16}$ However, the coagulation and osteoporosis risks restrict its clinical application. ${ }^{25,28,29}$ Developing safe and effective novel derivatives of Dex is of clinical importance. RGDF, RGDV, and RGDS, the so called RGD-peptides, are antiadhesive peptides and have been widely used to modify various drugs, of which motif-like action with integrins can potentially enhance the therapeutic efficacy and reduce the coagulation and osteoporosis risks of drugs. ${ }^{26,30}$ Aimed at this, the present study examines the development profile of covalent conjugates of RGD-peptides and Dex (RGDV-Dex,

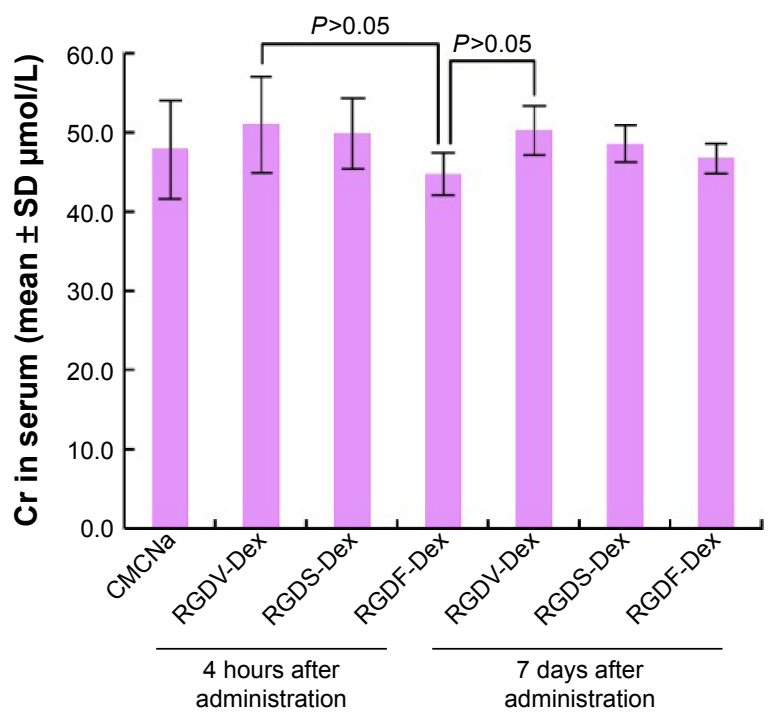

Figure 14 Serum Cr levels of the mice on which acute toxicity assay was performed, $\mathrm{n}=12$.

Abbreviations: $\mathrm{Cr}$, creatinine; $\mathrm{CMCNa}$, carmellose sodium; Dex, dexamethasone; RGDV, Arg-Gly-Asp-Val; RGDF, Arg-Gly-Asp-Phe; RGDS, Arg-Gly-Asp-Ser; SD, standard deviation.
RGDS-Dex, and RGDF-Dex) as new drugs. In vitro and in vivo, the activities of the conjugates are significantly higher than Dex itself and induce no coagulation risk. Figure 5 shows that of three conjugates against ConA-induced proliferation of spleen lymphocytes, RGDF-Dex exhibits the smallest $\mathrm{IC}_{50}$ value. Figure 6 indicates that of three conjugates affecting the implanted myocardium RGDF-Dex gives the longest survival time. Of three conjugates, in respect of the efficacies, RGDFDex is more worthy of developing as new drug. Besides, the in vitro and in vivo observations that the covalent introduction of RGDF benefit the efficacy are consistent with our previous work. ${ }^{31,32}$ Figure 7 shows that RGDF-Dex, RGDS-Dex, and RGDV-Dex, but not Dex itself, prolong the tail bleeding time of the mice. Taking RGDF-Dex, RGDS-Dex, and RGDV-Dex, but not Dex itself, inducing no osteoporosis into account, ${ }^{26}$ RGD-peptide modification leads to the complete relief of side effects of Dex. The safety of RGDF-Dex, RGDS-Dex, and RGDV-Dex was further evaluated with acute toxicity assay. Figures 12-14 indicate that even if the dose is 100 -fold higher than the minimal effective dose, three conjugates are still unable to induce toxic reaction. Furthermore, RGD-peptide modification leads to Dex having an additional antithrombotic activity.

The effect of nanofeature and size on bioactivity is an interesting profile. Showing the relationships between the bioactivities of small molecules with their TEM images, between the concentrations of small molecules with their TEM images, and between the structures of small molecules with their TEM images has been our interests. ${ }^{33-36}$ To elucidate the contribution of the nanoproperty to the advantages of three conjugates, this study systematically characterizes their nanofeatures. The Faraday-Tyndall effect, size distribution, and $\zeta$-potential of three conjugates in water ensure their properties as a true solution and their use as nanomedicine (Figure 4). The TEM images of three conjugates in $\mathrm{pH} 7.0$ and 2.0 ultrapure water of three concentrations clearly show the effect of $\mathrm{pH}$, concentration, and RGD-peptide sequence on the nanofeatures and size. As seen in Figure 2, RGDF sequence, $\mathrm{pH} 7.0$, and lower concentration benefit the formation of smaller nanoparticles. Since the particles of $100 \mathrm{~nm}$ in diameter have minimal probability of being entrapped by macrophages in blood circulation, ${ }^{37}$ the AFM images of small molecules in rat plasma were recorded in particular to simulate the feature of nanoparticles in blood circulation. ${ }^{34-36}$ The AFM images and the diameters of RGDF-Dex nanoparticles (close to $100 \mathrm{~nm}$ ) shown in Figure 3 suggest that it can be safely delivered in blood circulation. 


\section{Conclusion}

The development of novel, effective, and safe derivatives is of practical importance for Dex therapy. Our previous data and the present study demonstrate that covalent modification of Dex with RGD-peptides provides a strategy to enhance the anti-inflammatory activity, to prolong the survival time of the implanted myocardium, to minimize the side effects of osteoporosis and coagulation, to prevent the liver and the kidney from acute and chronic damage, and to provide a beneficial antithrombotic action. With respect to the size of the nanoparticles of three conjugates, RGDF-Dex is the most suitable for delivery in the circulation.

\section{Acknowledgments}

This work was supported by Beijing Municipal Science \& Technology Commission (Z141100002114049), the Project of Construction of Innovative Teams and Teacher Career Development for Universities and Colleges under Beijing Municipality, the NSFC (81172930, 81273379, 81373265, 81202412, 81373264), 863 program (2015AA020902), Beijing Talent Program (2014000026833ZK23) and Joint Research and Development of protective agents for low dose radiation injury (2014DFR30930).

\section{Disclosure}

The authors report no conflicts of interest in this work.

\section{References}

1. Barnes PJ. Glucocorticosteroids: current and future directions. $\mathrm{Br} J$ Pharmacol. 2011;163(1):29-43.

2. Barnes PJ. Mechanisms and resistance in glucocorticoid control of inflammation. J Steroid Biochem Mol Boil. 2010;120(2):76-85.

3. Goldbach-Mansky R, Lipsky PE. New concepts in the treatment of rheumatoid arthritis. Annu Rev Med. 2003;54(1):197-216.

4. van Vollenhoven RF. Treatment of rheumatoid arthritis: state of the art 2009. Nat Rev Rheumatol. 2009;5(10):531-541.

5. Buttgereit F, Saag KG, Cutolo M, da Silva JA, Bijilsma JW. The molecular basis for the effectiveness, toxicity, and resistance to glucocorticoids: focus on the treatment of rheumatoid arthritis. Scand J Rheumatol. 2005;34(1):14-21.

6. Sekhavat L, Davar R, Behdad S. Efficacy of prophylactic dexamethasone in prevention of postoperative nausea and vomiting. J Epidemiol Glob Health. 2015;5(2):175-179.

7. Low Y, White WD, Habib AS. Postoperative hyperglycemia after 4- vs 8-10-mg dexamethasone for postoperative nausea and vomiting prophylaxis in patients with type II diabetes mellitus: a retrospective database analysis. J Clin Anesth. 2015;27(7):589-594.

8. Chu C-C, Hsing C-H, Shieh J-P, Chien CC, Ho CM, Wang JJ. The cellular mechanisms of the antiemetic action of dexamethasone and related glucocorticoids against vomiting. Eur J Pharmacol. 2014;722(5):48-54.

9. Venkitaraman R, Lorente D, Murthy V, et al. A randomised Phase 2 trial of dexamethasone versus prednisolone in castration-resistant prostate cancer. Eur Urol. 2015;67(4):673-679.

10. Badawy AA, El Sakka A. Preoperative gabapentin alone or in combination with dexamethasone on postoperative pain relief after abdominal hysterectomies. A randomized controlled trial. Egypt J Anaesth. 2015; 31(2):107-113.
11. Boyer DS, Yoon YH, Belfort R Jr, et al. Three-year, randomized, shamcontrolled trial of dexamethasone intravitreal implant in patients with diabetic macular edema. Ophthalmology. 2014;121(10):1904-1914.

12. Parikh K, Hall M, Mittal V, et al. Comparative effectiveness of dexamethasone versus prednisone in children hospitalized with asthma. J Pediatr. 2015;167(3):639-644.

13. Zhan Y, Zou S, Hua F. High-dose dexamethasone modulates serum cytokine profile in patients with primary immune thrombocytopenia. Immunol Lett. 2014;160(1):33-38.

14. Cochrane AB, Husain AN, Anderson AS, Kim AY, Fedson SE. Increased rejection rates in cardiac transplant associated with dexamethasone. Steroids. 2008;73(4):441-448.

15. Fuchs KM, Coustan DR. Immunosuppressant therapy in pregnant organ transplant recipients. Semin Perinatol. 2007;31(6):363-371.

16. Weisel K, Dimopoulos M, Song KW, et al. Pomalidomide and low-dose dexamethasone improves health-related quality of life and prolongs time to worsening in relapsed/refractory patients with multiple myeloma enrolled in the MM-003 randomized phase III trial. Clin Lymphoma Myeloma Leuk. 2015;15(9):519-530.

17. van Osch D, Dieleman JM, Nathoe HM, et al. Intraoperative high-dose dexamethasone in cardiac surgery and the risk of rethoracotomy. Ann Thorac Surg. 2015;100(6):2237-2242.

18. Kale Y, Aydemir O, Ceylan O, Bas AY, Demirel N. Hypertrophic cardiomyopathy after a single dose of dexamethasone in a preterm infant. Pediatr Neonatol. 2015;56(4):268-270.

19. Bunge JJH, van Osch D, Dieleman JM, et al. Dexamethasone for the prevention of postpericardiotomy syndrome: a dexamethasone for cardiac surgery substudy. Am Heart J. 2014;168(1):126-131.

20. Yu HC, Luo YX, Peng H, Kang L, Huang MJ, Wang JP. Avoiding perioperative dexamethasone may improve the outcome of patients with rectal cancer. Eur J Surg Oncol. 2015;41(5):667-673.

21. Wróbel A, Serefko A, Wlaź P, Poleszak E. The depressogenic-like effect of acute and chronic treatment with dexamethasone and its influence on the activity of anti-depressant drugs in the forced swim test in adult mice. Prog Neuropsychopharmacol Biol Psychiatry. 2014;54(15):243-248.

22. Makrydima SF, Pistiki AC, Chrelias CG, et al. The immunomodulatory and anti-apoptotic effect of dexamethasone in imminent preterm labor: an experimental study. Eur J Pharmacol. 2014;730(5):31-35.

23. Hitzert MM, Van Braeckel KN, de Bok M, Maathuis CG, Roze E, Bos AF. Functional outcome at school age of preterm-born children treated with high-dose dexamethasone. Early Hum Dev. 2014;90(6): 253-258.

24. Ren K, Dusad A, Yuan F, et al. Macromolecular prodrug of dexamethasone prevents particle-induced peri-implant osteolysis with reduced systemic side effects. J Control Release. 2014;175(10):1-9.

25. Ren H, Liang D, Jiang X, et al. Variance of spinal osteoporosis induced by dexamethasone and methylprednisolone and its associated mechanism. Steroids. 2015;102:65-75.

26. Yu H, Mei S, Li Z, Zhao M, Wang Y, Zhu H. RGD-peptides modifying dexamethasone: to enhance the efficacy of anti-inflammation and limit the risk of osteoporosis. Med Chem Commun. 2015;6:1345-1351.

27. Liaw J-W, Tsai S-W, Lin H-H,Yen T-C, Chen B-R. Wavelength-dependent Faraday-Tyndall effect on laser-induced microbubble in gold colloid. J Quant Spectrosc Radiat Transfer. 2012;113(17):2234-2242.

28. Zamagnia E, Valdrè L, Palareti G, Cavo M. Prevention of VTE in multiple myeloma patients. Thromb Res. 2007;120(6):S133-S136.

29. Musallam KM, Dahdaleh FS, Shamseddine AI, Taher AT. Incidence and prophylaxis of venous thromboembolic events in multiple myeloma patients receiving immunomodulatory therapy. Thromb Res. 2009; 123(5):679-686.

30. Xiong Y, Zhao M, Wang C, Chang HW, Peng S. Improved antiosteoporosis potency and reduced endometrial membrane hyperplasia during HRT with estrogen-RGD peptide conjugates. J Med Chem. 2007;50(14): 3340-3353.

31. Li N, Kang G, Gui L, et al. Novel Cu(II)-RGD-octapeptides: synthesis, coordination mode, in vitro anti-platelet aggregation/in vivo antithrombotic evaluation and correlation of sequence with nano-structure. Nanomedicine 2011;7(4):403-409. 
32. Wang Y, Wu J, Kang G, et al. Novel nano-materials, RGD-tetrapeptidemodified $17 \beta$-amino-11 $\alpha$-hydroxyandrost-1,4-diene-3-one: synthesis, self-assembly based nano-images and in vivo anti-osteoporosis evaluation. J Mater Chem. 2012;22(11):4652-4659.

33. Gui L, Zhao M, Wang Y, Qin Y, Liu J, Peng S. Synthesis, nano-features, in vitro thrombus lysis activity and in vivo thrombolytic activity of poly- $\alpha$, $\beta$-aspartyl-L-alanine. Nanomedicine (Lond). 2010;5(5): 703-714.

34. Wu J, Wang Y, Wang Y, et al. $\mathrm{Cu}^{2+}$-RGDFRGDS: exploring the mechanism and high efficacy of nanoparticles in anti-thrombotic therapy. Int J Nanomedicine. 2015;10:2925-2938.
35. Li S, Wang Y, Wang F, et al. Small molecule PZL318: forming fluorescent nanoparticles capable of tracing their interactions with cancer cells and activated platelets, slowing tumor growth and inhibiting thrombosis. Int J Nanomedicine. 2015;10:5273-5292.

36. Jin S, Wang Y, Zhu H, et al. Nano-sized aspirin-Arg-Gly-Asp-Val: delivery of aspirin to thrombus by a target carrier Arg-Gly-Asp-Val tetrapeptide. ACS Nano. 2013;7(9):7664-7673.

37. Fujita Y, Mie M, Kobatake E, Construction of nanoscale protein particle using temperature-sensitive elastin-like peptide and polyaspartic acid chain. Biomaterials. 2009;30(20):3450-3457. 


\section{Supplementary materials \\ Optical spectra}

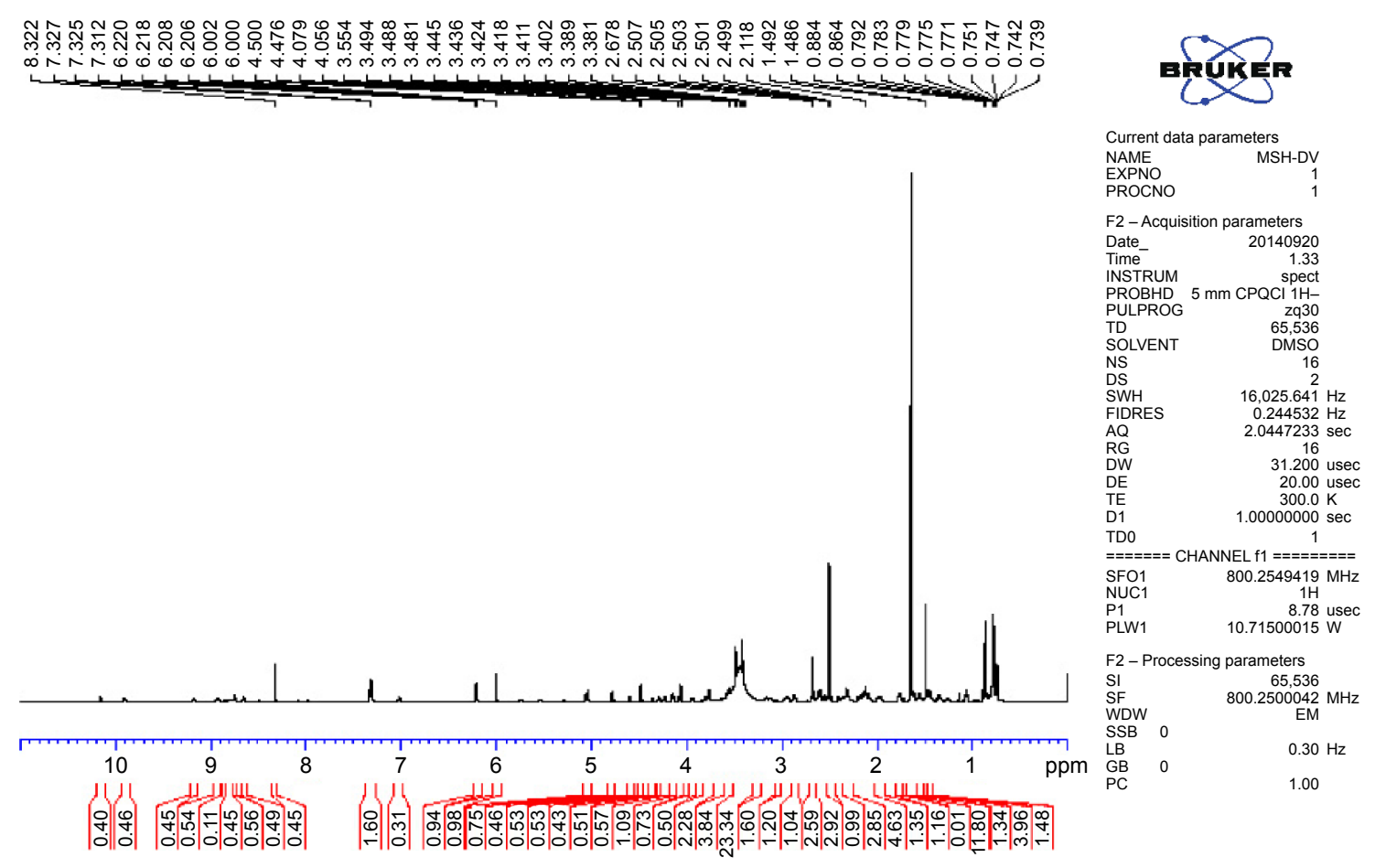

Figure SI 'H NMR of RGDV-Dex.

Abbreviations: 'H NMR, proton nuclear magnetic resonance; RGDV, Arg-Gly-Asp-Val; Dex, dexamethasone.

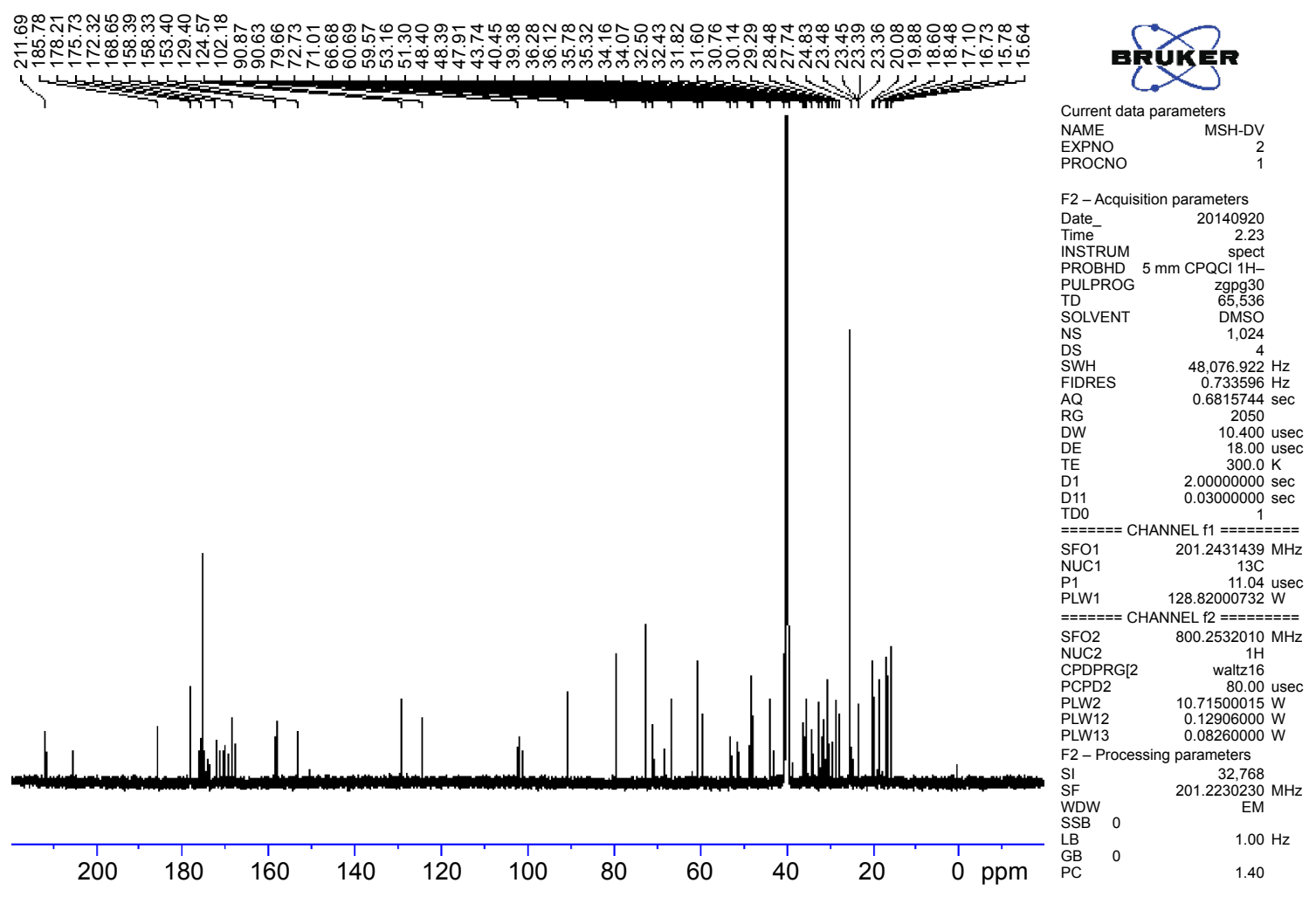

Figure S2 ${ }^{13} \mathrm{C}$ NMR of RGDV-Dex.

Abbreviations: ${ }^{13} \mathrm{C}$ NMR, carbon-1 3 nuclear magnetic resonance; RGDV, Arg-Gly-Asp-Val; Dex, dexamethasone. 


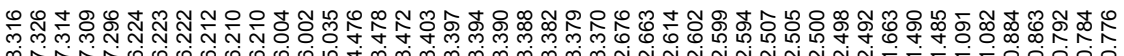
or

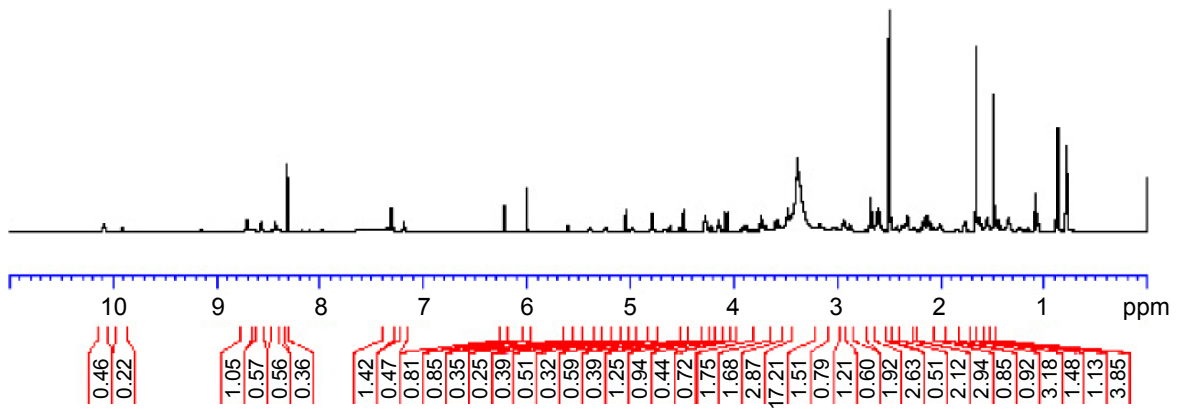

Figure S3 'H NMR of RGDS-Dex.

Abbreviations: 'H NMR, proton nuclear magnetic resonance; RGDS, Arg-Gly-Asp-Ser; Dex, dexamethasone.
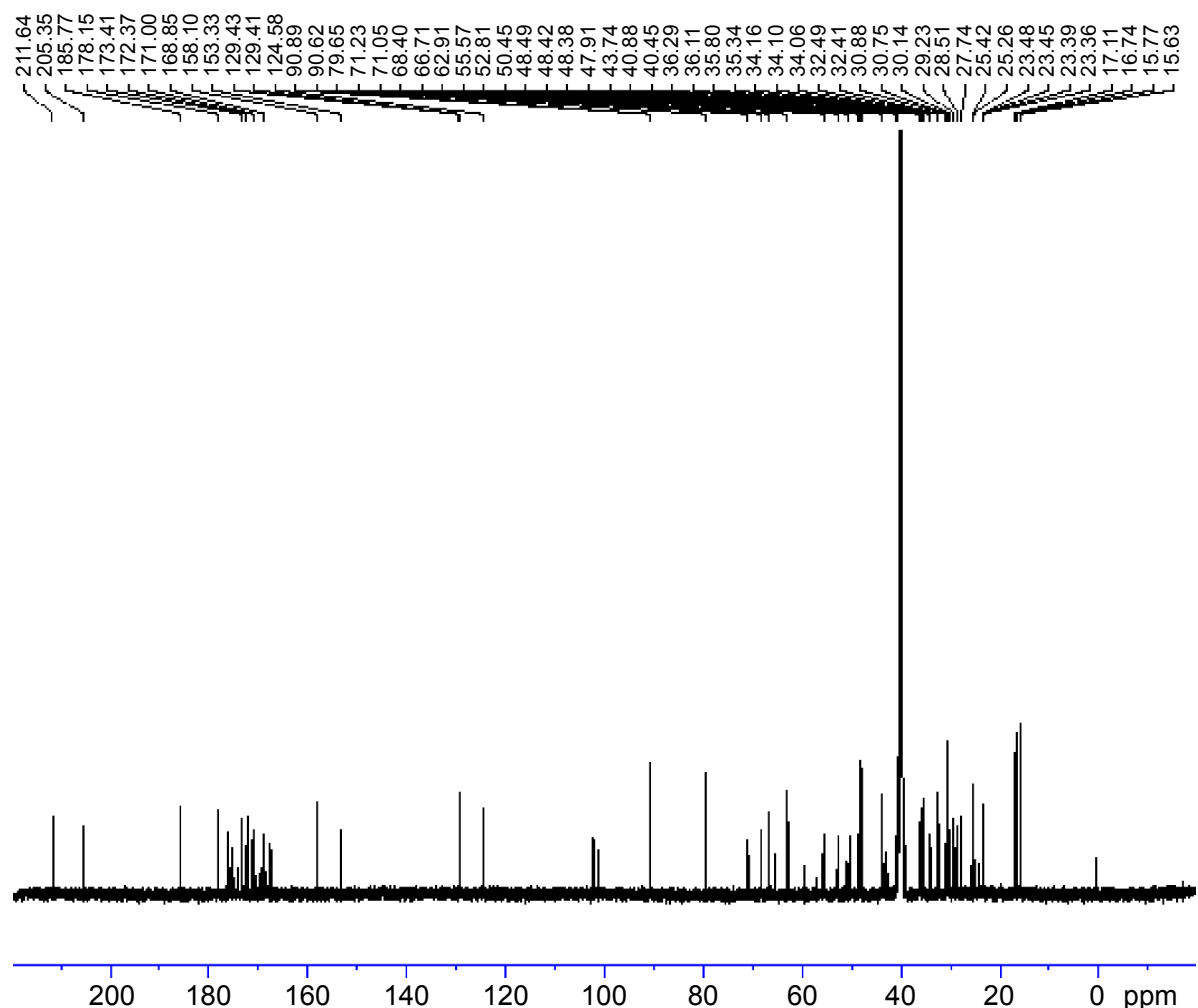

\section{Gर्Eer}

Current data parameters

NAME MSH-DS

EXPNO

F2 - Acquisition parameters

Date_ $\quad 20140920$

Time

spect
INSTRUM

PULPROG

PUD
TDOB

SOLVENT

NS
DS
SWH

DS

FIDRES
AQ
RG
DW

$\mathrm{DW}$
$\mathrm{DE}$
$\mathrm{TE}$

TE
D1

zq30
65,536
DMSO
16

16

16,025.641 Hz

$2.0447233 \mathrm{sec}$

16
31.200 usec

31.200 usec
20.00 usec

$300.0 \mathrm{~K}$

TD 11

SFO1
S00.2549419 MHz

$\begin{array}{lr}\text { SFO1 } & 800.2549419 \mathrm{MHz} \\ \text { NUC1 } & 1 \mathrm{H}\end{array}$

$\begin{array}{lr}\text { P1 } & 8.78 \text { usec } \\ \text { PLW1 } & 10.71500015 \mathrm{~W}\end{array}$

F2 - Processing parameters

$\begin{array}{ll}\mathrm{F} 2 & \text { - Processing parameters } \\ \mathrm{SI} & 65,536\end{array}$

$800.2500047 \mathrm{MHz}$

SSB 0

$\begin{array}{ll}\text { LB } & \\ \text { GB } & 0\end{array}$

$0.30 \mathrm{~Hz}$

1.00

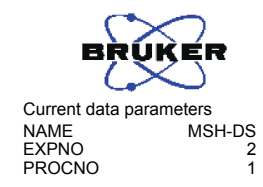

F2 - Acquisition parameters

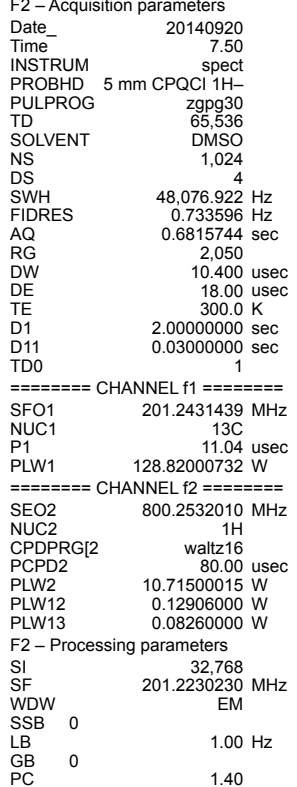

1.40

Figure $\mathbf{S 4}{ }^{13} \mathrm{C}$ NMR of RGDS-Dex

Abbreviations: ${ }^{13} \mathrm{C}$ NMR, carbon- 13 nuclear magnetic resonance; RGDS, Arg-Gly-Asp-Ser; Dex, dexamethasone. 


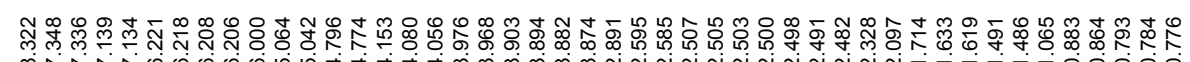
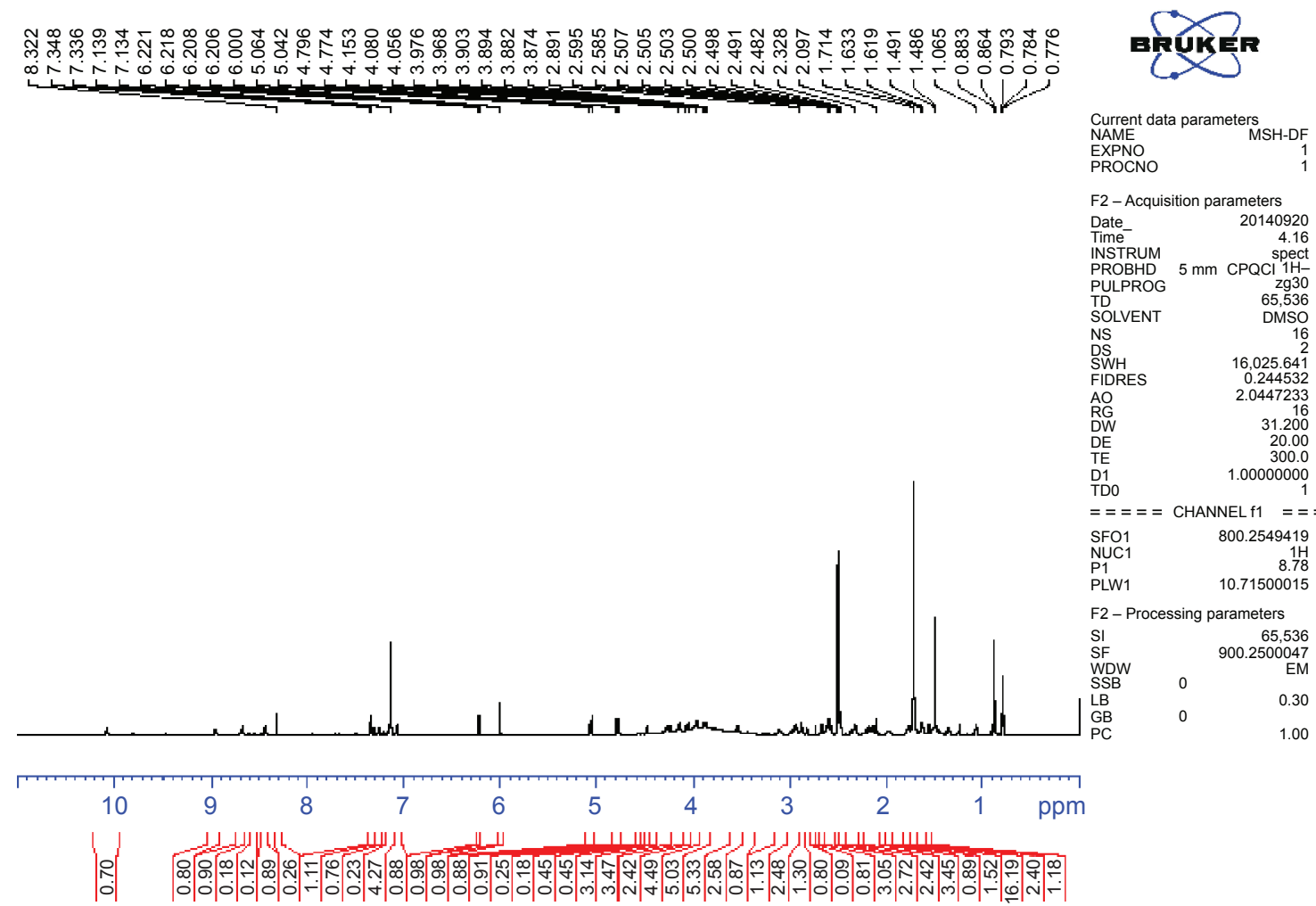

F2 - Acquisition parameters

Date 20140920

$\begin{array}{lr}\text { Time } & 4.16 \\ \text { INSTRUM } & \text { spect }\end{array}$

PROBHD $5 \mathrm{~mm} \mathrm{CPQCI} 1 \mathrm{H}-$

$\begin{array}{lr}\text { PULPROG } & \text { zg30 } \\ \text { TD } & 65,536 \\ \text { SOLVENT } & \text { DMSO }\end{array}$

$\begin{array}{lr}\text { NS } & 2 \\ \text { DS } & 2 \\ \text { SWH } & 16,025.641 \mathrm{~Hz} \\ \text { FIDRES } & 0.244532 \mathrm{~Hz}\end{array}$

AO $\quad 2.0447233 \mathrm{sec}$

$\begin{array}{lr}R G & 16 \\ D W & 31.200 \mathrm{usec} \\ \mathrm{DE} & 20.00 \mathrm{usec}\end{array}$

D1 $1.00000000 \mathrm{sec}$

$====$ CHANNELI $1==-=$

SFO1

$\begin{array}{lr}\text { NUC1 } & 800.2549419 \mathrm{MHz} \\ \text { P1 } & 8.78 \mathrm{usec}\end{array}$

PLW1 $10.71500015 \mathrm{~W}$

F2 - Processing parameters

$\begin{array}{lr}\text { SI } & 65,536 \\ \text { SF } & 900.2500047 \\ \text { WDW } & \text { EM }\end{array}$

$\begin{array}{lll}\text { WDW } & & \text { EM } \\ \text { SSB } & 0 & 0.30 \mathrm{~Hz}\end{array}$ PC

1.00

Figure S5 'H NMR of RGDF-Dex.

Abbreviations: 'H NMR, proton nuclear magnetic resonance; RGDF, Arg-Gly-Asp-Phe; Dex, dexamethasone.
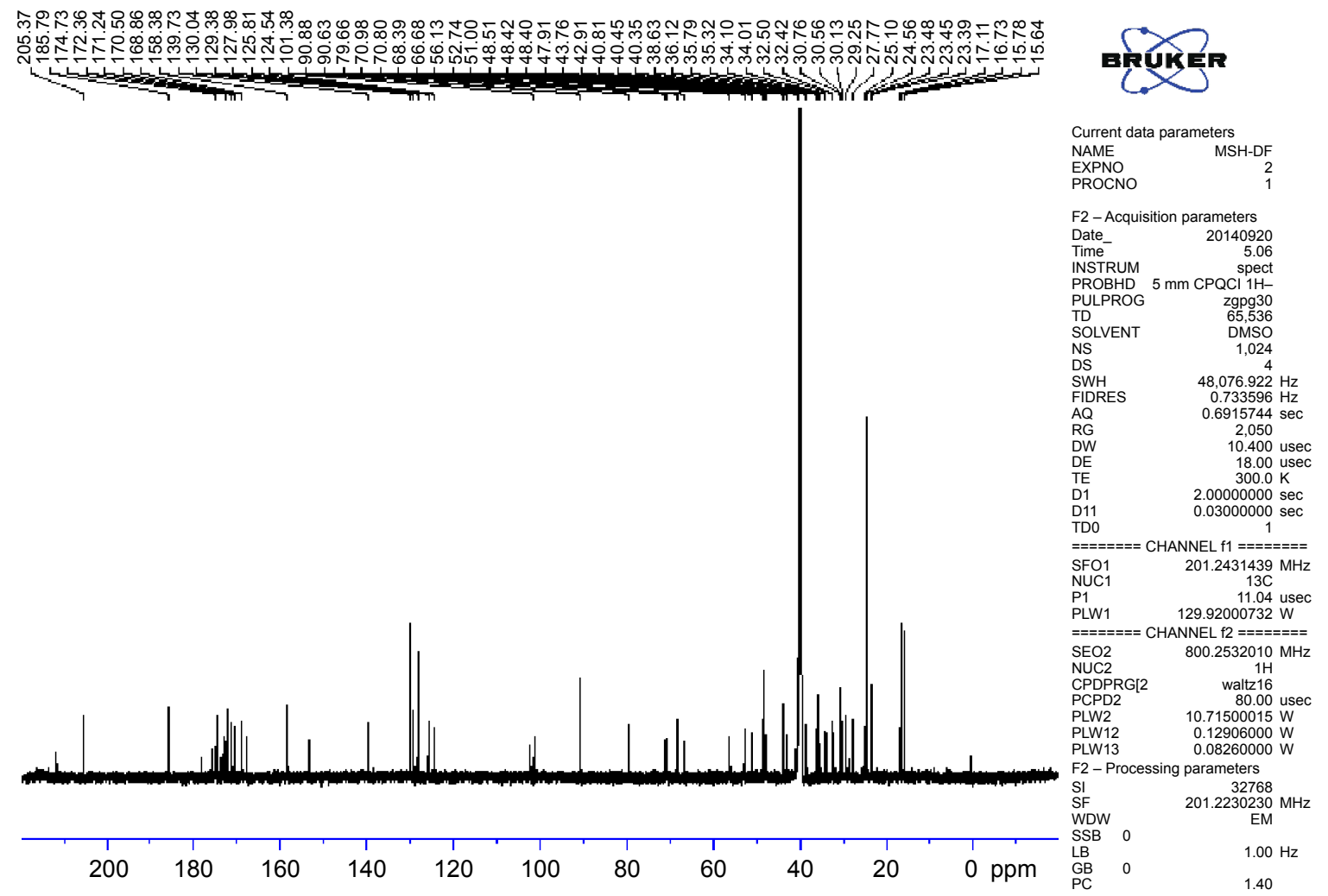

Figure S6 ${ }^{13} \mathrm{C}$ NMR of RGDF-Dex.

Abbreviations: ${ }^{13} \mathrm{C}$ NMR, carbon-13 nuclear magnetic resonance; RGDF, Arg-Gly-Asp-Phe; Dex, dexamethasone. 


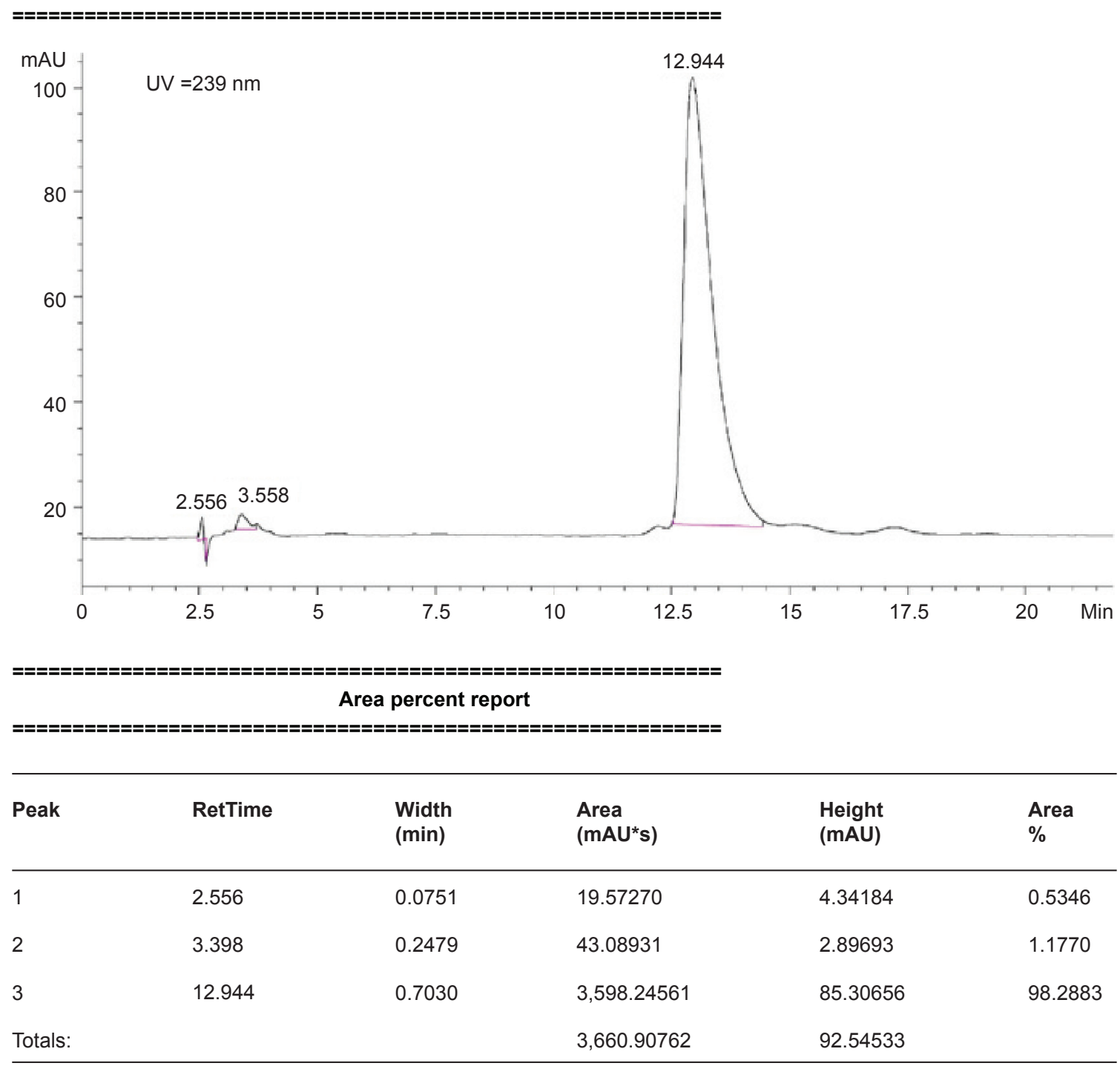

Figure S7 HPLC chromatogram of RGDF-Dex.

Note: Mobile phase: $\mathrm{CH}_{3} \mathrm{OH}:$ Water $=15 \%: 85 \%$.

Abbreviations: HPLC, high performance liquid chromatography; RGDF, Arg-Gly-Asp-Phe; Dex, dexamethasone. 


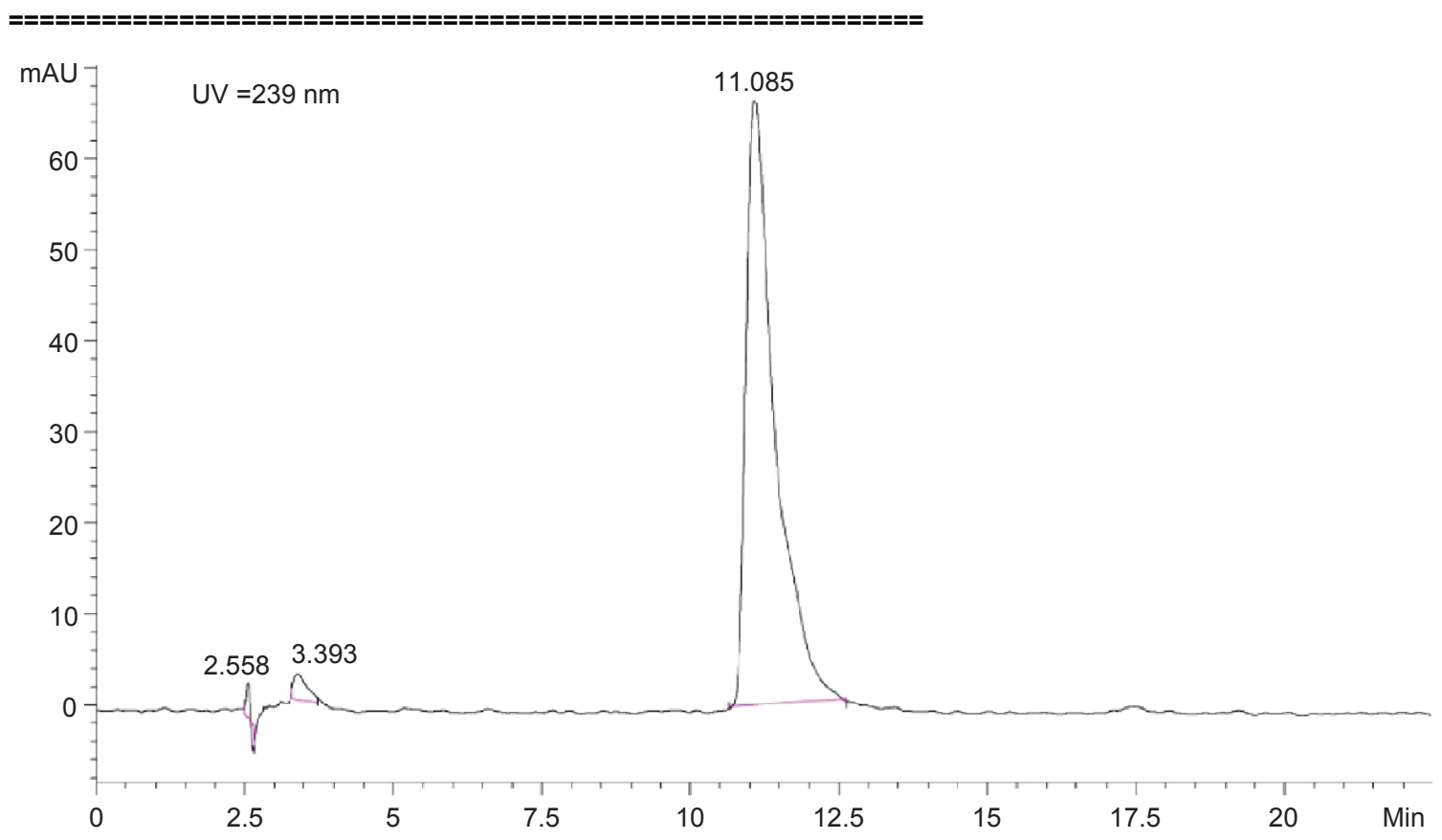

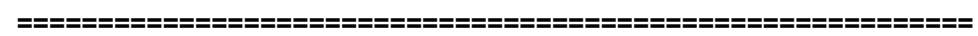

Area percent report

\begin{tabular}{|c|c|c|c|c|c|}
\hline Peak & RetTime & $\begin{array}{l}\text { Width } \\
\text { (min) }\end{array}$ & $\begin{array}{l}\text { Area } \\
\text { (mAU*s) }\end{array}$ & $\begin{array}{l}\text { Height } \\
\text { (mAU) }\end{array}$ & $\begin{array}{l}\text { Area } \\
\%\end{array}$ \\
\hline 1 & 2.563 & 0.0678 & 15.65087 & 3.84969 & 0.6743 \\
\hline 2 & 3.392 & 0.2701 & 45.14389 & 2.78515 & 1.9450 \\
\hline 3 & 11.085 & 0.5647 & $2,260.27368$ & 66.71368 & 97.3807 \\
\hline Totals: & & & $2,321.06844$ & 73.34853 & \\
\hline
\end{tabular}

Figure S8 HPLC chromatogram of RGDV-Dex.

Note: Mobile phase: $\mathrm{CH}_{3} \mathrm{OH}:$ Water $=15 \%: 85 \%$

Abbreviations: HPLC, high performance liquid chromatography; RGDV, Arg-Gly-Asp-Val; Dex, dexamethasone. 


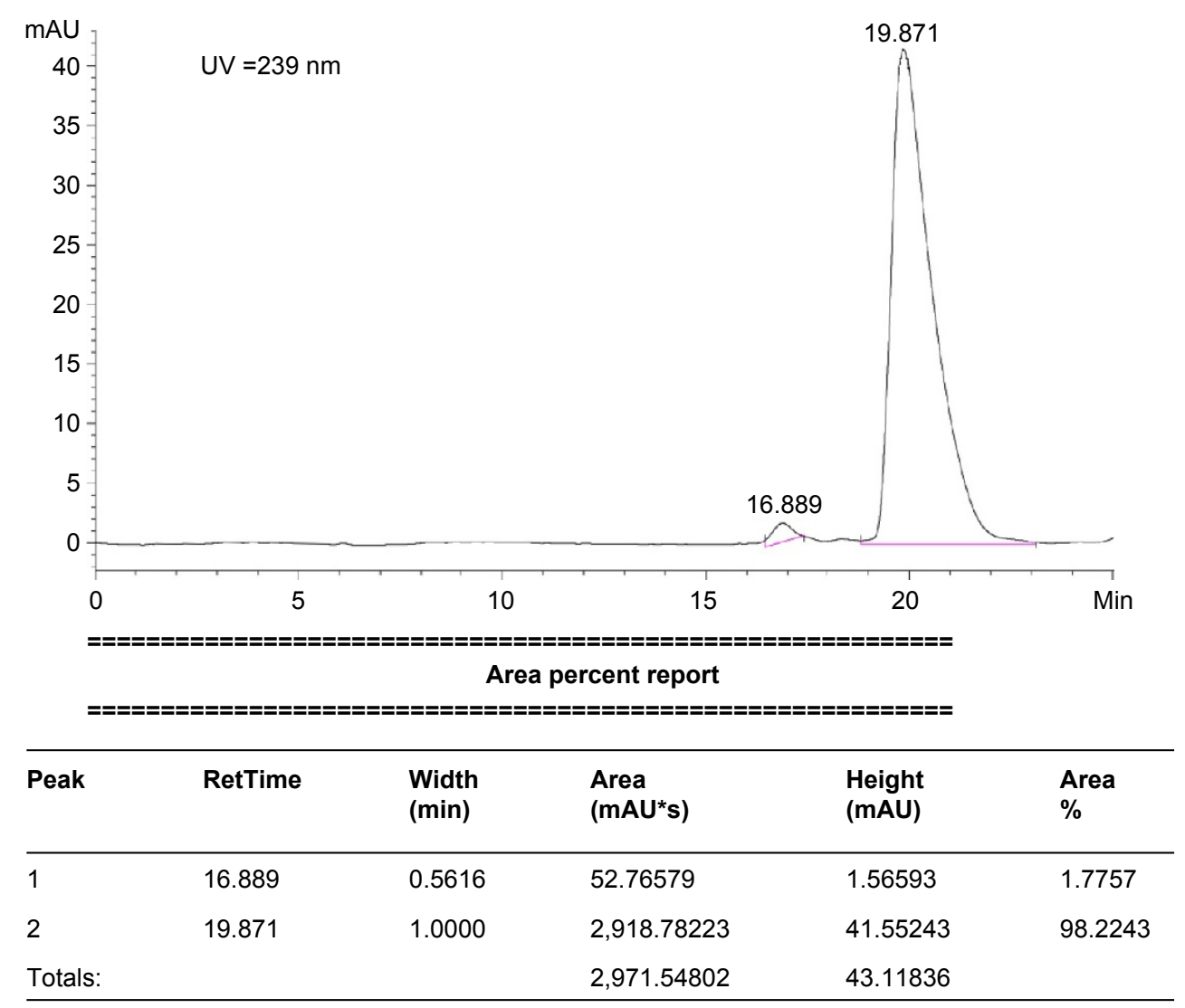

Figure S9 HPLC chromatogram of RGDS-Dex.

Note: Mobile phase: $\mathrm{CH}_{3} \mathrm{OH}:$ Water=85\%: $15 \%$

Abbreviations: HPLC, high performance liquid chromatography; RGDS, Arg-Gly-Asp-Ser; Dex, dexamethasone.

\section{Publish your work in this journal}

Drug Design, Development and Therapy is an international, peerreviewed open-access journal that spans the spectrum of drug design and development through to clinical applications. Clinical outcomes, patient safety, and programs for the development and effective, safe, and sustained use of medicines are a feature of the journal, which has also been accepted for indexing on PubMed Central. The manuscript management system is completely online and includes a very quick and fair peer-review system, which is all easy to use. Visit http://www.dovepress.com/testimonials.php to read real quotes from published authors.

Submit your manuscript here: http://www.dovepress.com/drug-design-development-and-therapy-journal 